ARTÍCULOS 



\title{
LA CORONA: UN ACERCAMIENTO A LAS POLÍTICAS DEL REINO KAAN DESDE UN CENTRO SECUNDARIO DEL NOROESTE DEL PETÉN
}

\author{
Marcello A. Canuto \\ Tulane University \\ Tomás BarRientos Q. \\ Universidad del Valle de Guatemala
}

\begin{abstract}
Resumen: El Proyecto Regional Arqueológico La Corona estudia la región del noroeste de Petén, Guatemala, donde se localiza la antigua ciudad maya de La Corona, que recientemente fue identificada como el Sitio Q. La investigación ha incluido las excavaciones de arquitectura monumental, asentamientos, la elaboración de mapas, el uso de sensores remotos y la realización de estudios paleoclimatológicos y ecológicos. Desde el punto de vista de los modelos de la organización política, las investigaciones en La Corona presentan una oportunidad para estudiar la naturaleza y las relaciones políticas de los sitios secundarios. Los datos epigráficos relatan una afiliación directa entre La Corona y la dinastía gobernante en Calakmul, por lo que el primer centro seguramente fungió como punto clave para las estrategias de expansión de Calakmul por las Tierras Bajas Mayas durante los siglos vi y vil d.C. Aquí se presentan algunos resultados obtenidos en las investigaciones llevadas al cabo entre 2005 y 2009.
\end{abstract}

Palabras clave: La Corona, Sitio Q, noroeste Petén, organización política, sitios secundarios.

AвstRAct: The La Corona Regional Archaeological Project is studying the northwestern Peten region (Guatemala), where the ancient Maya city of La Corona is located. This site has been recently identified as the unknown Site $\mathrm{Q}$. The research at La Corona has included excavations of monumental and settlement architecture, mapping, use of remote sensing and ecological and paleo-climate studies. Viewed from the political organization models, investigations at La Corona present an opportunity to study the nature and political relations of secondary sites. Epigraphic data show a direct affiliation between La Corona and the ruling dynasty of Calakmul, suggesting that La Corona could have been a key center for the expansionistic strategies of Calakmul during the sixth and seventh centuries A.D. In this paper we present some of the results obtained in the investigations carried out between 2005 and 2009.

KeYwords: La Corona, Site Q, Northwestern Peten, Political Organization, Secondary sites.

ReCEPCIÓN: 30 de junio del 2010.

ACEPTACIÓN: 12 de octubre del 2010. 



\title{
LA CORONA: UN ACERCAMIENTO A LAS POLÍTICASDELREINOKAANDESDEUNCENTRO SECUNDARIO DEL NOROESTE DEL PETÉN
}

\author{
Marcello A. Canuto \\ Tulane University \\ TOMÁs BARrientos Q. \\ Universidad del Valle de Guatemala
}

\section{Introducción}

El sitio arqueológico La Corona se ubica en el noroccidente de Petén (figura 1) y su estudio se ha iniciado hace apenas cinco años, poco después de haberse comprobado su identificación con el llamado Sitio Q (Canuto et al., 2005; Guenter, 2005; Stuart, 2001). Después de tres cortas temporadas de campo, se ha establecido que La Corona constituye uno de los centros más importantes de la región noroccidental del Petén. El estudio del sitio La Corona se enfoca esencialmente en la comprensión de las relaciones políticas de la cultura maya en el periodo Clásico. La Corona parece ser un sitio de tamaño modesto y de importancia limitada, pero sus numerosos y detallados monumentos desmienten esta caracterización simplista. La Corona representa una fuente importante de información sobre Calakmul, además de cumplir una función como centro secundario durante la expansión de este último. Asimismo, la zona en la cual está ubicada La Corona es una de las menos investigadas del Petén, particularmente el tramo de casi 40 $\mathrm{km}$ que se sitúa entre este sitio y la frontera norte de Guatemala. La posición de un sitio de tan alta importancia en una zona desconocida justifica entonces el interés en la investigación de La Corona y sus alrededores.

Generalmente la historia de las antiguas ciudades mayas se reconstruye a partir de su descubrimiento e investigación. En el caso de La Corona su importancia fue reconocida mucho antes de su propio descubrimiento, debido a la interpretación de sus monumentos saqueados. Para explicar de mejor forma la singularidad de La Corona se ofrece una exposición de la forma en que se ha desarrollado el estudio del sitio en las últimas décadas.

\section{Antecedentes: el descubrimiento del Sitio Q}

Gracias a la prospección petrolera de los años sesenta, se abrieron brechas en muchos lugares previamente inaccessibles del Petén, por lo que muchos sitios 


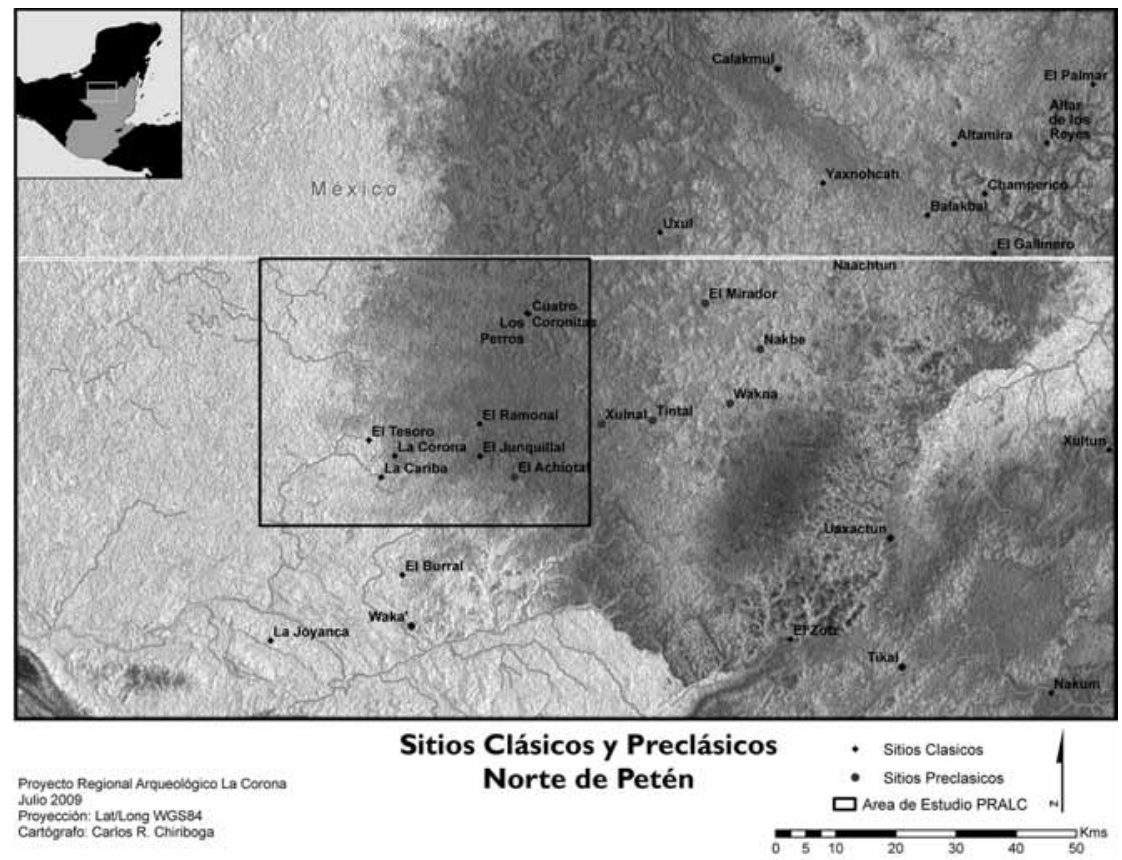

Figura 1. Mapa del noroccidente del Petén. Mapa: Carlos R. Chiriboga.

desconocidos fueron accesibles a los saqueadores. De hecho, en 1965 el Art Institute of Chicago adquirió un panel esculpido de procedencia desconocida, que ilustra dos jugadores de pelota y con una inscripción que presenta la fecha de 690 d.C. (figura 2). La inscripción identifica a uno de los protagonistas con el nombre Chak Ak'aach Yuk ("Pavo Grande"). Este panel de piedra caliza pertenecía a un grupo de más de veinte esculturas similares que fueron compradas por coleccionistas privados en los Estados Unidos y Europa. Aunque se apreció mucho la maestría artística de estas piezas, no se pensó que provenían del mismo lugar.

Pocos años después de la aparición de estas esculturas en el mercado de antiguiedades, el epigrafista Peter Mathews (1988) notó que las inscripciones de estos monumentos compartían muchos rasgos epigráficos, iconográficos y estilísticos. Mathews sugirió entonces que este grupo de monumentos procedían del mismo lugar, un sitio todavía desconocido al cual Mathews dio el sobrenombre de Sitio Q, o sea, “isitio qué?". Mathews agrupó todas estas piezas con rasgos parecidos, creando así el catálogo de monumentos del Sitio Q. Después de muchas búsquedas, cambios y adiciones, el catálogo ha llegado casi a 30 esculturas individuales, las cuales hoy se encuentran en museos y colecciones privadas por todo el mundo.

Los primeros análisis de los monumentos del Sitio Q enfatizaban su estilo artístico (v.g., Coe, 1973: 3). Por su fino detalle y las imágenes de jugadores de pe- 


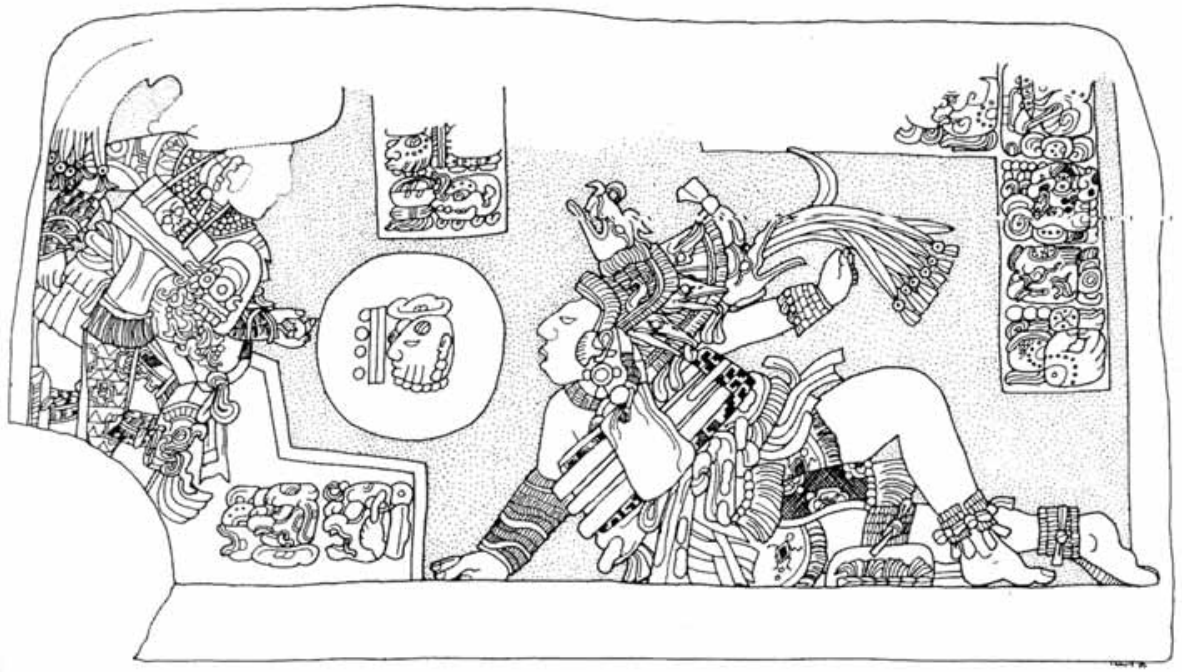

Figura 2. Monumento Misceláneo 1 de La Corona. Dibujo: Linda Schele

lota, varios investigadores sugirieron que este sitio estaba ubicado en la región del Usumacinta, donde son comunes los paneles esculpidos de tamaño pequeño. Con los avances en el análisis epigráfico, el desciframiento de los textos reveló los nombres e historia de los gobernantes del Sitio Q (Mathews, 1979; Ringle, 1985; Schele y Grube, 1994), así como referencias frecuentes al glifo emblema de Calakmul, que consiste en una cabeza de serpiente (Marcus, 1973, 1976; Martin, 1996, 1997; Martin y Grube, 1995; Schele y Freidel, 1990: 456-457; Stuart y Houston, 1994). Aunque los textos comprobaron que el Sitio Q formaba parte de la esfera de influencia y control de Calakmul, la gran expansión regional de este reino y la presencia tan amplia de su gilfo emblema no hicieron posible avanzar mucho en la identificación geográfica del Sitio Q.

En la década de los ochenta Ian Graham (1988) hizo el primer mapa del importante sitio de El Perú (su nombre original fue Waka'), que se ubica a $115 \mathrm{~km}$ al suroeste de Calakmul y cuenta con una considerable cantidad de estelas y otras esculturas. El registro de los monumentos de Waka' incluyó el estudio de varios restos de estelas saqueadas (“cadáveres”), y confirmó que dos de ellas que se habían incluido en el corpus de monumentos del Sitio Q eran originarias de Waka' (Graham, 1988; Miller, 1974; Schele y Mathews, 1991: 250). Estas primeras correspondencias entre los monumentos de un emplazamiento conocido y el Sitio Q, apoyaron la teoría de que este último era Waka' (Hellmuth, 1996). Sin embargo, después de un reconocimiento exhaustivo en dicho sitio, se concluyó que allí no existían suficientes contextos apropiados para acomodar la gran mayoría de los monumentos en el corpus del Sitio Q (Graham, 1988: 126). 
Al mismo tiempo, los avances en el estudio epigráfico de los monumentos del Sitio Q permitieron identificar el posible nombre de esta ciudad, en la forma de un glifo que se lee sak nikte' ("flor blanca") (figura 3). Además, debido a que este glifo nunca estaba acompañado por los títulos k'uhul ajaw ("sagrado señor"), se hizo claro que no era un glifo emblema, sino solamente un topónimo que denotaba el nombre original del lugar o de alguna parte dentro del sitio (Stuart y Houston, 1994: 39). La carencia de un glifo emblema propio para el Sitio Q y el hallazgo de un glifo emblema de Waka' confirmó que ambos eran sitios distintos. También se definió que los gobernantes del Sitio Q estuvieron subordinados a los de Calakmul.

La interpretación de los vínculos estrechos con Calakmul se ha podido realizar con base en la identificación de varios individuos nombrados en los monumentos del Sitio Q, los cuales son: 1) gobernantes o príncipes de Calakmul (Schele y Grube, 1994: 22-23); 2) princesas o hijas de gobernantes de Calakmul que se unieron en matrimonio con los gobernantes locales (Freidel y Guenter, 2003; Stuart, Martin y Houston, 2008); y 3) gobernantes locales claramente identificados como vasallos de Calakmul (Houston y Stuart, 2001: 67; Martin, 2001: 183). En pocas palabras, los textos del Sitio $Q$ enumeraban con gran detalle varias conexiones familiares entre los gobernantes del Sitio Q y la dinastía real de Calakmul.

Aunque la ubicación del Sitio Q todavía se ignoraba, varios datos indicaban que debía encontrarse entre Waka' y Calakmul. Entre estas evidencias se pueden mencionar la similitud con ciertos monumentos de Waka', el registro de varios viajes a Calakmul por parte de los gobernantes locales, la llegada de varias mujeres reales de Calakmul al Sitio Q, y la carencia de un glifo emblema propio. Por lo tanto, se hizo claro que este sitio no estaba ubicado en el Usumacinta, sino en un lugar más cerca de Waka' y Calakmul, es decir, en el noroeste del Petén, donde se encuentra el Parque Nacional Laguna del Tigre.

En la década de los noventa, el uso de sensores remotos permitió que Tom Sever y Dan Lee, científicos de la NASA, pudiesen identificar varios rasgos arquitec-

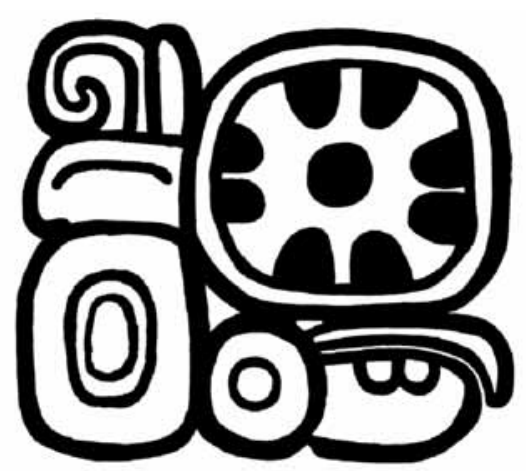

Figura 3. Glifo sak nikte. Dibujo: Stanley Guenter 
tónicos monumentales en la región al norte de Waka' y sur de Calakmul. Específicamente vislumbraron unos rasgos lineares, tipo sacbé, que indicaban un posible "camino real" entre Waka' y Calakmul. Al mismo tiempo, chicleros en el noroeste del Petén descubrieron un nuevo sitio, lo cual fue informado a Jim Nations, quien en aquel entonces trabajaba para Conservation International. En 1996, Nations, Sever y Lee montaron una expedición al nuevo sitio, y durante su visita notaron que contaba con monumentos, por lo que decidieron buscar la ayuda de epigrafistas.

En mayo de 1997, Ian Graham y David Stuart del Museo Peabody de la Universidad de Harvard visitaron el sitio (Graham, 1997), y durante su estadía Graham hizo el primer mapa bosquejo del sitio. Su mapeo descubrió una plaza central (Grupo A) con dos estructuras piramidales al este y un complejo tipo acrópolis al oeste. Al mismo tiempo, Stuart registró los monumentos esculpidos, notando que los textos no solamente mencionaban al gobernante "Pavo Grande", sino también se referían al lugar sak nikte’. Con estos vínculos, Stuart empezó a contemplar la posibilidad de que éste fuese el Sitio $Q$.

Sin embargo, Graham observó que había poca evidencia de saqueo de monumentos, es decir, no habían localizado los restos de monumentos ("cadáveres”) que hubieran sido aserrados para aligerar su transporte. Debido a esto, combinado con diferencias en estilo, tipo y calidad entre los monumentos visibles del sitio y los del Sitio Q, Graham inicialmente dudó que aquel fuera el lugar buscado desde hacía décadas (Graham, 1997, 2002). Consecuentemente, siendo precavidos sobre la relación entre este sitio nuevo y el Sitio Q, Graham y Stuart nombraron al primero La Corona, debido a un complejo arquitectónico de cinco estructuras alienadas que parecían una corona de cinco puntas.

A pesar de las dudas sobre la posibilidad de que La Corona fuera el Sitio Q (Chase y Chase, 1998: 21; Hansen, 1997), Stuart (2001) reforzó dicha hipótesis mediante un análisis petrográfico conducido por Chris Hayward de la Universidad de Manchester. Este estudio indicó que la piedra de un monumento del Sitio Q era bastante parecida a varias muestras de piedras provenientes de La Corona (Stuart, 2001). Sin embargo, se propuso también que el Sitio Q probablemente representaba una serie de pequeños sitios aliados con Calakmul (v.g., Martin, 2001: 183) en vez de un solo sitio todavía desconocido.

En 2005 y 2006 se organizaron dos expediciones al sitio La Corona por parte del Proyecto El Perú-Waka', dirigido por David Freidel y Héctor Escobedo (Canuto et al., 2005; Canuto et al., 2006; Acuña, 2006; Marken y Guenter, 2007). Las expediciones tenían como propósito investigar la correlación entre La Corona y el Sitio Q propuesta por Stuart (2001). Dos años después, en 2008, se llevó al cabo la primera temporada del Proyecto Regional Arqueológico La Corona (PRALC), dirigido por Marcello Canuto y Tomás Barrientos (Canuto y Barrientos, 2009). Esta fue una temporada corta y preliminar, enfocada mayormente en establecer las bases para un estudio a largo plazo. Por lo tanto, se continuaron algunas exploraciones generales en el sitio y su región circundante, y se definieron aspectos de logística para realizar estudios más amplios y detallados en el futuro. 


\section{Investigaciones en La Corona}

No obstante, aún cuando se haya resuelto el misterio del Sitio Q, todavía queda mucho por hacer, especialmente en lo relacionado a su temporalidad de ocupación y sus vínculos con otras ciudades contemporáneas.

El Proyecto Regional Arqueológico La Corona (PRALC) pretende investigar una zona del Petén poco estudiada, donde La Corona representa el sitio clásico maya con arquitectura monumental más noroccidental de Guatemala. Aunque ya se han hecho algunos estudios de reconocimiento (Kaufman y Leal, 1988; Leal y López, 1993; Leal et al., 1988), no se han realizado investigaciones intensivas en esta zona. De hecho, del norte de La Corona hasta la frontera con Guatemala y México, yacen más de $30 \mathrm{~km}$ de territorio inexplorado donde podrían estar ubicados varios sitios monumentales.

La zona de estudio abarca la región entre Waka' y La Corona hasta la frontera norte de Guatemala, que incluye unos $50 \mathrm{~km}$ al oeste de la Cuenca del Mirador. En total, la zona mediría casi $2200 \mathrm{~km}^{2}$. Claramente, no se supone que se logre un estudio arqueológico exhaustivo de esta zona completa, pero se espera que mediante el uso de sensores remotos se pueda explorar la región entre La Corona y la frontera norte. El área se encuentra en varias zonas distintas de la Reserva Biosfera Maya, que son: Parque Nacional Laguna del Tigre, Zona de Manejo Especial Laguna del Tigre y Corredor Biológico. En cuanto a concesiones, están Paixbán al nordeste, San Andrés (AFISAP), Carmelita, y La Colorada. La zona de estudio está en la jurisdicción del municipio de San Andrés, departamento de Petén.

El Proyecto Regional Arqueológico La Corona (PRALC) inició en 2008 (Canuto y Barrientos, 2009) como seguimiento a varias investigaciones preliminares llevadas al cabo por el Proyecto El Perú-Waka' entre 2005 y 2006 (Canuto et al., 2005; Canuto et al., 2006). Como es de esperarse, estas temporadas iniciales han proporcionado un mapa preliminar del centro del sitio y datos bastante preparatorias, que no solo dan indicios cronológicos sino también constituyen la base para planificar estudios intensivos a largo plazo en lo que se refiere a asentamiento, arquitectura, subsistencia, etc.

\section{Reinterpretaciones epigráficas recientes}

Se iniciará con los datos de tipo epigráfico debido a que el estudio de inscripciones ha sido el referente inicial para los estudios de La Corona y sus alrededores. Hay que recordar que la identificación del Sitio Q se realizó gracias al análisis comparativo de los textos de varias esculturas ubicadas en Estados Unidos y Europa, y es sorprendente que hoy en día todavía siguen apareciendo paneles glíficos en colecciones privadas (Stuart, Martin y Houston, 2008). Por esta razón, aunque las inscripciones de La Corona (Sitio Q) han sido estudiadas con gran detalle, éstas están sujetas a reinterpretaciones a medida que surgen nuevos textos y/o datos arqueológicos. 
Cabe puntualizar también que la interpretación de los textos de La Corona no se limita solamente al punto de vista de un epigrafista, ya que el proyecto cuenta con el trabajo de especialistas como David Stuart, Stanley Guenter y Joanne Baron. Además, se cuenta con la colaboración constante de otros epigrafistas como Simon Martin y Stephen Houston para buscar la mayor objetividad de las lecturas de los textos, así como su relación con los avances arqueológicos. Por esta razón, en agosto de 2008 se realizó un pequeño encuentro para estandarizar la nomenclatura de monumentos, afinar la secuencia dinástica y discutir los distintos eventos y personajes que se mencionan en las inscripciones.

Como resultado de dicha reunión, se han definido 67 esculturas con inscripciones provenientes de La Corona, entre las cuales se pueden clasificar 7 paneles, 2 estelas, 5 altares, 3 escalinatas y 7 monumentos misceláneos (tabla 1). En cuanto a las escalinatas, éstas se han definido mediante la agrupación estilística y temática de bloques individuales con glifos o personajes. Así, la Escalinata Jeroglífica 1 consta de 63 bloques; la Escalinata Jeroglífica 3, de ocho bloques; y la Escalinata Jeroglífica 2, de 14 bloques. Por ejemplo, los bloques con jugadores de pelota fueron agrupados como parte de la Escalinata Jeroglífica 2 (figuras 4a, 4 b y 4c), y por su tamaño y estilo se asociaron con otros bloques glíficos. En cuanto a su temática y personajes, se dudaba si esta escalinata en realidad provenía de La Corona o si pudo proceder de otro sitio, como se había argumentado en ocasiones anteriores. Sin embargo, gracias al descubrimiento y a la toma de fotografías del "cadáver" de un panel en La Corona durante la temporada 2008, se logró determinar que corresponde a uno de los paneles glíficos que conforman dicha escalinata. No obstante, al analizar los textos de las escalinatas, se ha determinado que todavía queda por ubicar una gran cantidad de bloques, ya sea in situ o en museos y colecciones privadas.

Es de notar que a pesar de que está tan vinculada con la dinastía de Calakmul, la familia real de La Corona carece del título de k'ujul ajaw, por lo que no existe un glifo emblema para el sitio. Esta privación da la impresión de que el sitio La Corona y sus gobernantes eran de importancia política secundaria. Sin embargo, esto se desmiente por la cercana relación de parentesco entre las familias reales de los dos centros.

Por lo tanto, desde el punto de vista de los modelos de organización política maya, La Corona revela una serie de contradicciones en las relaciones políticas de los sitios secundarios, las cuales se pueden esclarecer por medio de la investigación arqueológica, como ha sido el caso de la zona del Usumacinta. En La Corona, los datos epigráficos muestran que los modelos no deben confundir el rango político de un sitio con el estatus sociopolítico de sus gobernantes. Es decir, no se puede definir a La Corona como un centro secundario gobernado por aliados de Calakmul, sino como un centro de función e importancia específica, como una colonia, un puesto fronterizo o la sede de un ramal de la propia dinastía de Calakmul. 
Tabla 1

\begin{tabular}{|c|c|c|c|c|}
\hline \multicolumn{2}{|c|}{ Catálogo de La Corona } & Contexto arqueológico & \multirow{2}{*}{$\begin{array}{l}\text { Año } \\
2005\end{array}$} & Catálogo del Sitio Q \\
\hline Panel & 1 & Estructura 13R-5 & & \\
\hline Panel & 2 & Desconocido & ¿? & Panel 2 y $2 A$ \\
\hline Panel & 3 & Desconocido & ¿? & Panel 1 \\
\hline Panel & 4 & Desconocido & ¿? & Panel 4 \\
\hline Panel & 5 & Desconocido & ¿? & Panel 5 \\
\hline Panel & 6 & Desconocido & ¿? & Altar de Dallas \\
\hline & & (Estr. 13Q-1?) & & \\
\hline Panel & 7 & Estructura 13R-9 & 2006 & \\
\hline Friso Glifico 1 & Bloque 1 & Estructura $13 Q-4 B$ & 2005 & \\
\hline Friso Glífico 1 & Bloque 1I & Estructura 13Q-4B & 2005 & \\
\hline Escalinata Glífica 1 & Bloque 1 & Estructura 13Q-3 & 1997 & \\
\hline Escalinata Glífica 1 & Bloque II & Estructura $13 Q-3$ & 1997 & \\
\hline Escalinata Glifica 1 & Bloque III & Estructura $13 Q-3$ & 1997 & \\
\hline Escalinata Glifica 1 & Bloque IV & Estructura $13 Q-3$ & 1997 & \\
\hline Escalinata Glífica 1 & Bloque V & Estructura 13Q-3 & 1997 & \\
\hline Escalinata Glífica 1 & Bloque $\mathrm{VI}$ & Estructura 13Q-3 & 1997 & \\
\hline Escalinata Glifica 1 & Bloque VII & Estructura $13 Q-3$ & 1997 & \\
\hline Escalinata Glífica 1 & Bloque VIII & Estructura $13 Q-3$ & 1997 & \\
\hline Escalinata Glífica 1 & Bloque IX & Estructura 13Q-3 & 1997 & \\
\hline Escalinata Glífica 1 & Bloque $\mathrm{X}$ & Estructura 13Q-3 & 1997 & \\
\hline Escalinata Glifica 1 & Bloque XI & Estructura $13 Q-3$ & 1997 & \\
\hline Escalinata Glífica 1 & Bloque XII & Estructura 13Q-3 & 1997 & \\
\hline Escalinata Glífica 1 & Bloque XIII & Estructura 13Q-3 & 2008 & \\
\hline Escalinata Glifica 1 & Bloque XIV & Estructura $13 Q-3$ & 2008 & \\
\hline Escalinata Glifica 1 & Bloque XV & Estructura 13Q-3 & 2008 & \\
\hline Escalinata Glífica 1 & Bloque XVI & Estructura $13 Q-3$ & 2008 & \\
\hline Escalinata Glifica 1 & Bloque XVII & Estructura $13 Q-3$ & 2008 & \\
\hline Escalinata Glífica 1 & Bloque XVIII & Estructura 13Q-3 & 2008 & \\
\hline Escalinata Glífica 1 & Bloque XIX & Estructura 13Q-3 & 2008 & \\
\hline Escalinata Glifica 1 & Bloque XX & Estructura $13 Q-3$ & 2008 & \\
\hline Escalinata Glifica 1 & Bloque XXI & Estructura $13 Q-3$ & 2008 & \\
\hline Escalinata Glifica 1 & Bloque XXII & Estructura 13Q-3 & 2008 & \\
\hline Escalinata Glifica 2 & Bloque I & Estructura $13 Q-4$ & ¿? & Panel Glífico A \\
\hline Escalinata Glifica 2 & Blogue II & Estructura $13 Q-4$ & ¿? & Panel Glífico B \\
\hline Escalinata Glifica 2 & Bloque III & Estructura $13 Q-4$ & ¿? & Panel Glífico D \\
\hline Escalinata Glífica 2 & Bloque IV & Estructura 13Q-4 & ¿? & Panel Glífico C \\
\hline Escalinata Glífica 2 & Bloque V & Estructura $13 Q-4$ & ¿? & Kerr 9126 \\
\hline Escalinata Glifica 2 & Bloque VI & Estructura $13 Q-4$ & ¿? & Kerr 9128 \\
\hline Escalinata Glífica 2 & Bloque VII & Estructura 13Q-4 & 2006 & \\
\hline Escalinata Glifica 2 & Bloque VIII & Estructura $13 Q-4$ & ¿? & Kerr 9127 \\
\hline Escalinata Glífica 3 & Bloque I & Estructura $13 Q-2 / 6 ?$ & ¿? & Panel de Jugador de Pelota 2 \\
\hline Escalinata Glifica 3 & Bloque II & Estructura $13 Q-2 / 6 ?$ & ¿? & Panel de Jugador de Pelota 4 \\
\hline Escalinata Glífica 3 & Bloque III & Estructura $13 Q-2 / 6 ?$ & ¿? & Panel de Jugador de Pelota 3 \\
\hline Escalinata Glifica 3 & Bloque IV & Estructura $13 Q-2 / 6 ?$ & ¿? & Panel de Jugador de Pelota 6 \\
\hline Escalinata Glífica 3 & Bloque $\mathrm{V}$ & Estructura $13 Q-2 / 6 ?$ & ¿? & Panel de Jugador de Pelota 5 \\
\hline Escalinata Glifica 3 & Bloque $\mathrm{VI}$ & Estructura $13 Q-2 / 6 ?$ & ¿? & Panel Glífico 6 \\
\hline Escalinata Glifica 3 & Bloque VII & Estructura $13 Q-2 / 6 ?$ & ¿? & Panel Glífico 7 \\
\hline Escalinata Glifica 3 & Bloque VIII & Estructura $13 Q-2 / 6 ?$ & ¿? & Panel Glífico 1 \\
\hline
\end{tabular}




\begin{tabular}{|c|c|c|c|c|}
\hline \multicolumn{2}{|c|}{ Catálogo de La Corona } & Contexto arqueológico & Año & Catálogo del Sitio Q \\
\hline $\begin{array}{l}\text { Escalinata Glífica } 3 \\
\text { Escalinata Glifica } 3 \\
\text { Escalinata Glífica } 3 \\
\text { Escalinata Glífica } 3 \\
\text { Escalinata Glifica } 3 \\
\text { Escalinata Glífica } 3\end{array}$ & $\begin{array}{l}\text { Bloque IX } \\
\text { Bloque X } \\
\text { Bloque XI } \\
\text { Bloque XII } \\
\text { Bloque XIII } \\
\text { Bloque XIV }\end{array}$ & $\begin{array}{l}\text { Estructura } 13 \mathrm{Q}-2 / 6 ? \\
\text { Estructura } 13 \mathrm{Q}-2 / 6 ? \\
\text { Estructura } 13 \mathrm{Q}-2 / 6 ? \\
\text { Estructura } 13 \mathrm{Q}-2 / 6 ? \\
\text { Estructura } 13 \mathrm{Q}-2 / 6 ? \\
\text { Estructura } 13 \mathrm{Q}-2 / 6 ?\end{array}$ & $\begin{array}{l}\text { ¿? } \\
i ? \\
i ? \\
i ? \\
i ? \\
i ?\end{array}$ & $\begin{array}{r}\text { Panel Glífico } 9 \\
\text { Panel Glífico } 4 \\
\text { Panel Glífico } 8 \\
\text { Panel Glífico } 3 \\
\text { Panel Glífico } 5 \\
\text { Panel Glífico } 11\end{array}$ \\
\hline $\begin{array}{r}\text { Estela } \\
\text { Estela } \\
\text { Altar } \\
\text { Altar } \\
\text { Altar } \\
\text { Altar } \\
\text { Altar }\end{array}$ & $\begin{array}{l}1 \\
2 \\
1 \\
2 \\
3 \\
4 \\
5\end{array}$ & $\begin{array}{r}\text { Grupo D } \\
\text { Plaza Principal } \\
\text { Plaza Principal } \\
\text { Plaza Principal } \\
\text { Plaza Principal } \\
\text { Plaza Principal } \\
\text { Plaza Principal }\end{array}$ & $\begin{array}{l}1997 \\
1997 \\
1997 \\
1997 \\
1997 \\
1997 \\
1997\end{array}$ & \\
\hline $\begin{array}{l}\text { Misceláneo } \\
\text { Misceláneo } \\
\text { Misceláneo } \\
\text { Misceláneo } \\
\text { Misceláneo } \\
\text { Misceláneo } \\
\text { Misceláneo }\end{array}$ & $\begin{array}{l}1 \\
2 \\
3 \\
4 \\
5 \\
6 \\
7\end{array}$ & $\begin{array}{r}\text { Desconocido } \\
\text { Desconocido } \\
\text { Desconocido } \\
\text { Desconocido } \\
\text { Desconocido } \\
\text { Estructura 13Q-2 } \\
\text { Estructura } 13 Q-2 / 13 Q-3\end{array}$ & $\begin{array}{c}? \\
i ? \\
i ? \\
i ? \\
i ? \\
2008 \\
2008\end{array}$ & $\begin{array}{r}\text { Ballplayer Panel } 1 \\
\text { Panel } 3 \\
\text { Stela } 5 \\
\text { Panel Glífico } 2 \\
\text { Panel Glífico } 10\end{array}$ \\
\hline
\end{tabular}

Desde un principio fue evidente que la cantidad de monumentos en La Corona era inusual para un sitio de su tamaño, por lo que se espera no sólo encontrar esos fragmentos faltantes sino también nuevos monumentos. A partir de los estudios epigráficos relacionados con La Corona, cabe destacar la presencia de personajes asociados al glifo emblema con cabeza de serpiente, el cual se ha identificado como Kan o Kanal." Por lo tanto, se ha determinado que durante gran parte de su ocupación, los dirigentes de La Corona estuvieron estrechamente relacionados e incluso emparentados con los gobernantes de dicha entidad política. Ahora bien, el glifo emblema de serpiente se ha asociado tradicionalmente con la ciudad de Calakmul, pero recientes investigaciones arqueológicas (Esparza Olguin y Pérez Gutiérrez, 2009; Grube, 2004; Martin, 2004; Nalda, 2000, 2004; Velásquez García, 2004, 2005, 2008) apuntan a que Calakmul no fue la única capital del reino Kan, sino que el sitio de Dzibanché fue el centro de dicha dinastía durante el Clásico Temprano, en los siglos v y vi d.C.

Para ser más específicos, además de en Dzibanché, se han encontrado ejemplos del glifo Kan (así como los nominales de varios gobernantes como Yuknoom Ch'een I y "Testigo de Cielo") en varios sitios de Quintana Roo como El Resbalón, Pol Box y Yo'okop. Parece ser entonces que el asiento de poder del reino Kan se trasladó de Dzibanché a Calakmul entre los años 580 y 590 d.C. Como se verá más adelante, esto dificulta establecer la naturaleza de las relaciones entre La Corona

* N. del E.: se ha respetado la ortografía asentada por los autores. 


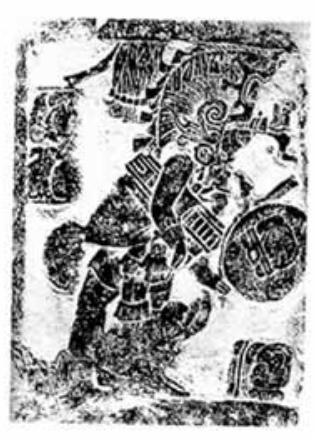

Bloque I

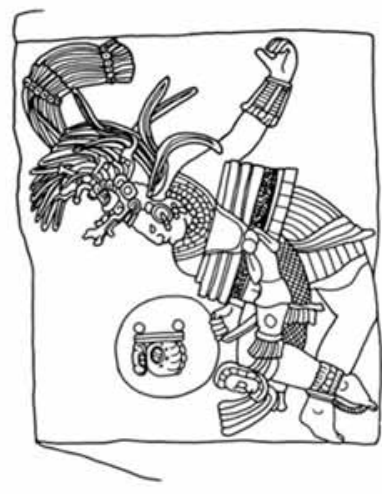

Bloque II

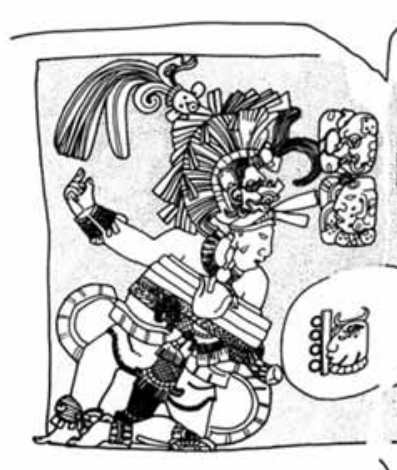

Bloque IV

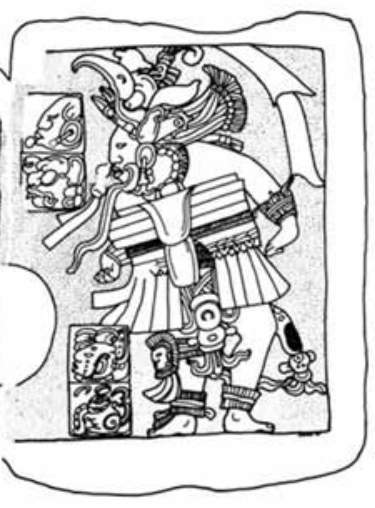

Bloque III

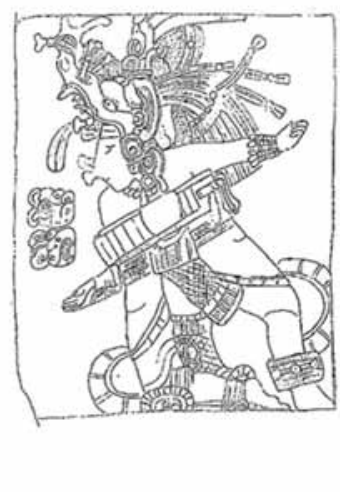

Bloque V

Figura 4a. Esculturas que componen la Escalinata Jeroglífica 2.

(Bloques I a V)

Dibujos: David Stuart, Linda Schele y Nikolai Grube 


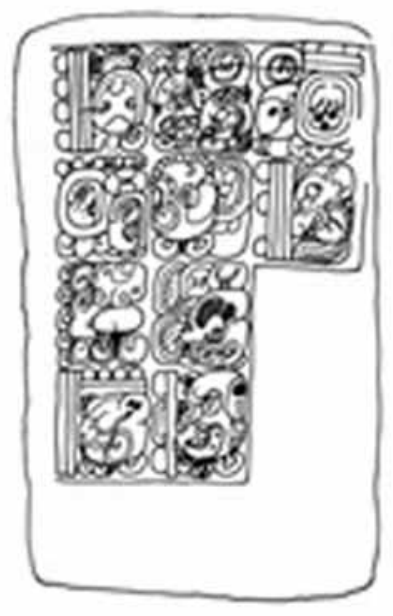

Bloque VI

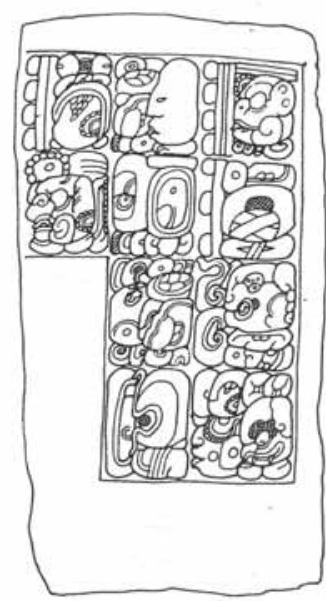

Bloque VII

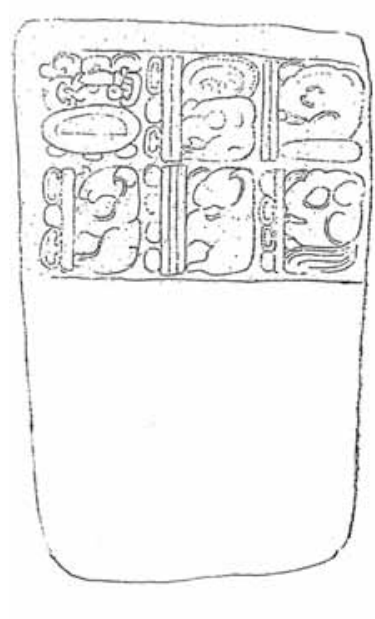

Bloque VIII

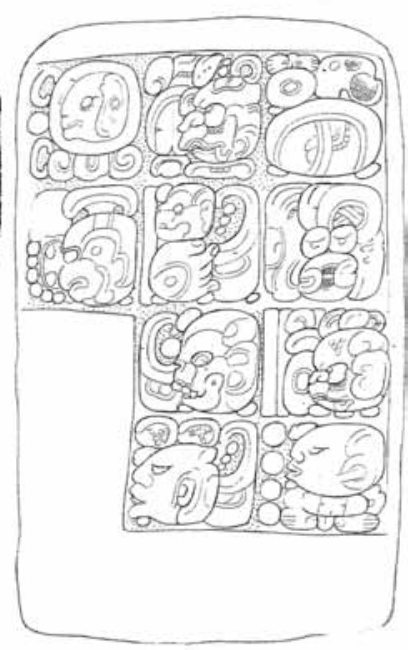

Bloque IX

Figura 4b. Esculturas que componen la Escalinata Jeroglífica 2. (Bloques VI a IX)

Dibujos: David Stuart, Linda Schele y Nikolai Grube 

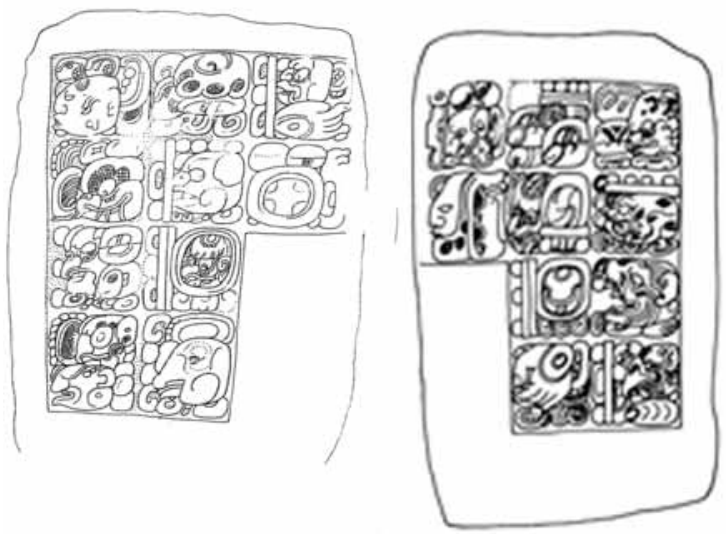

Bloque X

Bloque XI
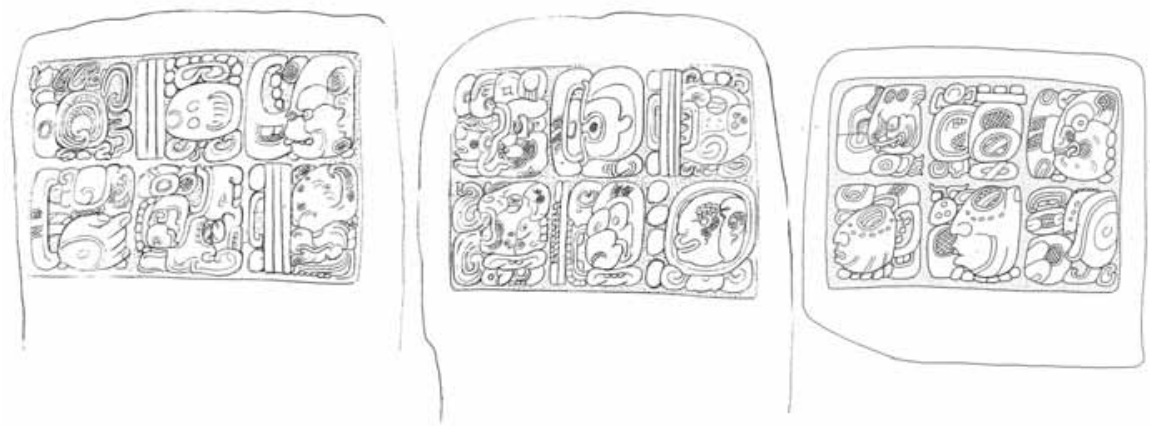

Bloque XII

Bloque XIII

Bloque XIV

Figura 4c. Esculturas que componen la Escalinata Jeroglífica 2.

(Bloques X a XIV)

Dibujos: David Stuart, Linda Schele y Nikolai Grube 
y el reino Kan durante el Clásico Temprano, así como también cuestiona el origen de dicha dinastía en el norte de Petén, así como su continuidad en la región de Calakmul. Por lo tanto, todavía se está definiendo el verdadero significado del glifo emblema Kan, y hay que tomar en cuenta que su expansión posiblemente no se trató de un proceso ancestral, sino fue el resultado de estrategias políticas establecidas en el siglo vi d.C. por gobernantes como Yuknoom Ch'een el Grande.

Otro avance epigráfico de suma importancia es la interpretación reciente del Panel 6 (Martin, 2008) (figura 5), también conocido como el Panel de Dallas, en el cual se registra la llegada de tres mujeres del reino Kan en distintas épocas de la historia de La Corona. La primera de ellas llega en el año de 520 d.C., cuando la capital pudo ubicarse en Dzibanché. La otra mujer fue hija del gobernante Yuknoom Ch'een, y llegó en el 679 d.C. para contraer matrimonio con el gobernante local, K'inich Yook. Finalmente, la llegada de la tercera mujer ocurrió en el 721 d.C., cuando se dedicó el monumento y cuando el poder de Calakmul ya estaba en proceso de declinación. La importancia de estos eventos radica en que confirma la relación directa entre La Corona y el reino Kan y evidencia nuevamente el papel político que jugaron las mujeres nobles en este tipo de actividades diplomáticas. Por lo tanto, si se toma en cuenta que el Altar 4 registra la llegada de otra mujer en el año 791 d.C., se puede afirmar que la historia política de La Corona estuvo fuertemente influenciada por alianzas matrimoniales con otros poderes.

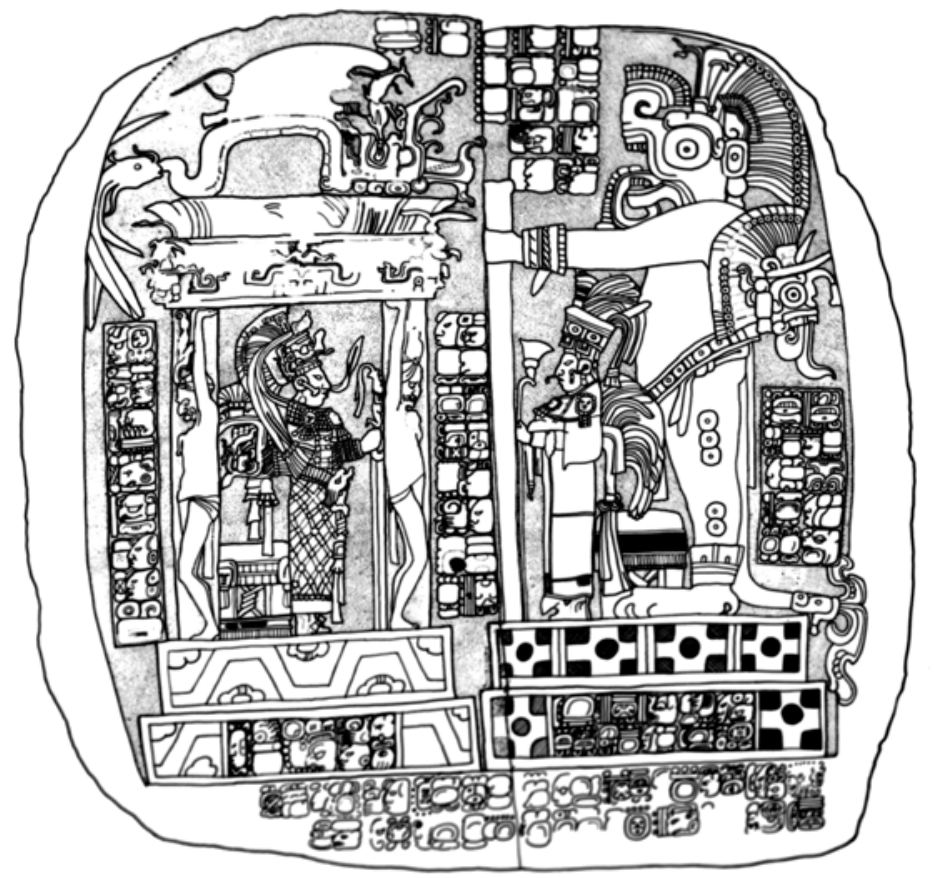

Figura 5. Panel 6 de La Corona. Dibujo: Linda Schele 
De cualquier forma, de acuerdo con los datos arqueológicos y epigráficos, se han establecido tres grandes periodos asociados con la secuencia dinástica del sitio (figura 6). El primero corresponde al Clásico Temprano, donde el registro histórico es casi nulo, con excepción de la llegada de la primera mujer del reino Kan. Posteriormente, entre el 615 y el 695 d.C., se define la "era dorada" de las inscripciones, cuando existió un vínculo estrecho entre La Corona y la expansión política de Calakmul a manos de Yuknoom Ch'een y su sucesor. Finalmente, el tercer periodo corresponde a la decadencia de Calakmul después de su derrota a manos de Jasaw Chaan K'awiil de Tikal, y al desarrollo de La Corona como un sitio más independiente, lo cual permitió el aumento de expresiones locales y el incremento de centros a sus alrededores.

\section{Estudios regionales}

Por tratarse de una zona desconocida arqueológicamente, los estudios llevados a cabo en la región de La Corona han aportado una gran cantidad de datos que son claves para la interpretación del sitio y de toda la zona. Las entrevistas con antiguos chicleros y pobladores de San Andrés han permitido elaborar un panorama de la densidad de sitios alrededor de La Corona y hacia la frontera mexicana. Por el momento sólo se han podido visitar algunos de aquellos, como es el caso de Los Perros y Los Cuyos, que se encuentran en la zona de Paixbán. Es posible que la densidad de sitios al norte de La Corona sea alta, si se toman en cuenta los resultados obtenidos por Ivan Šprajc en el sur Campeche (Šprajc, 2002-2004, 2008), que muestran un asentamiento continuo hacia el norte de la región de El Mirador. No obstante, aún falta establecer la presencia de un sitio mayor en esa región, que pudo conectar a La Corona con otros sitios como Uxul (Grube, 2005; Grube y Paap, 2006, 2007), es decir, con la ruta hacia Calakmul.

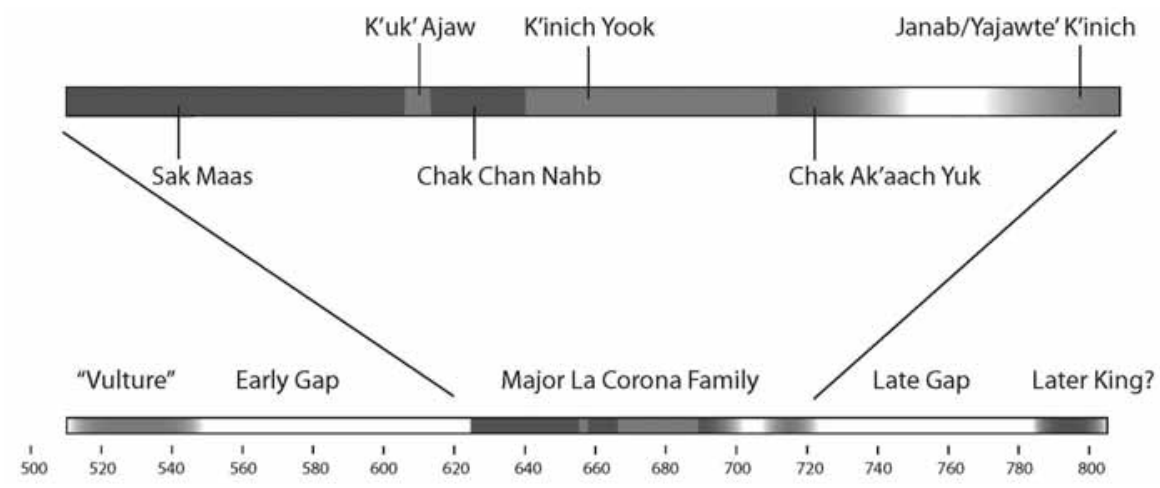

Figura 6. Cronología dinástica de La Corona. Gráfico de Joanne Baron 


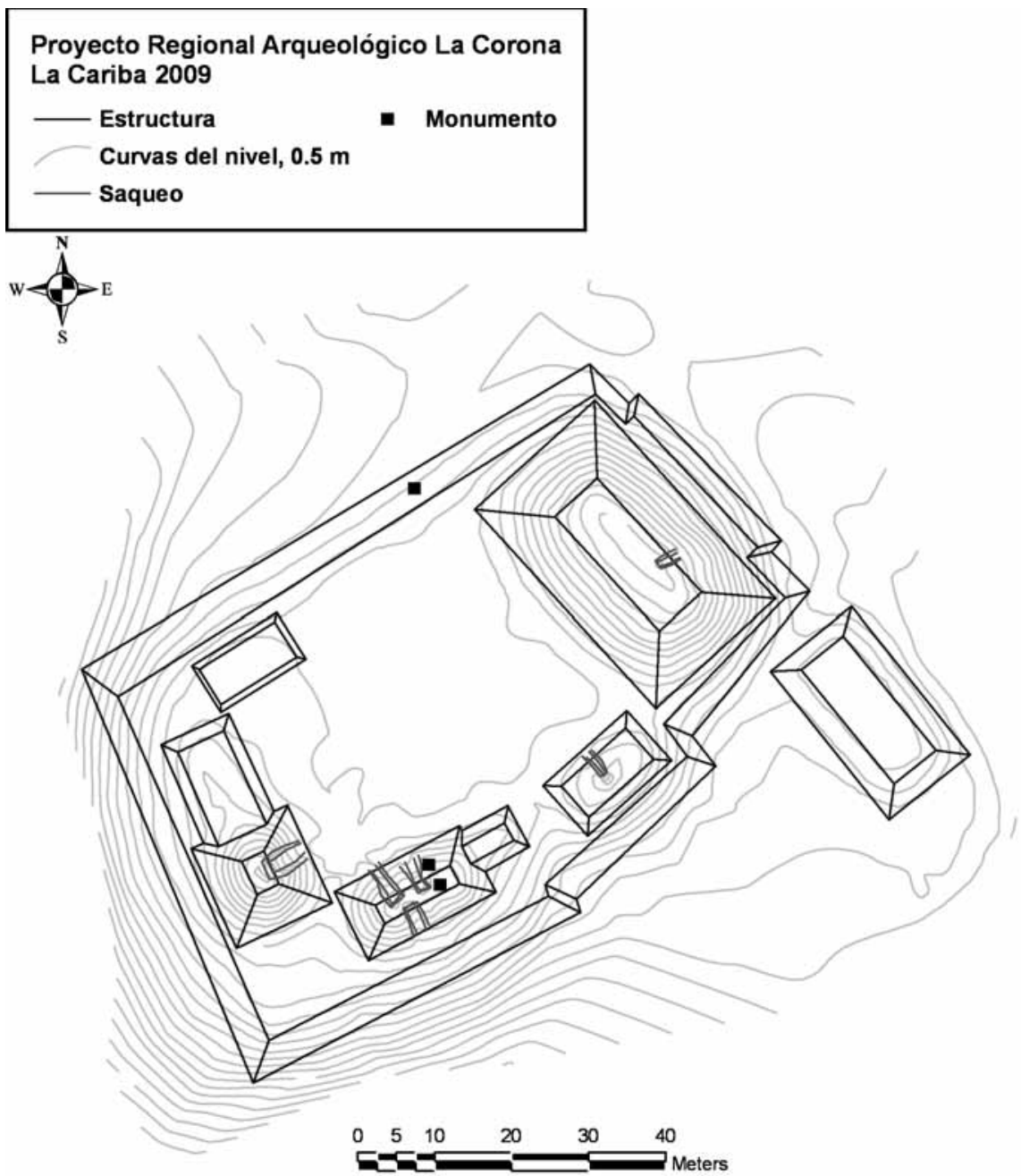

Figura 7. Mapa de La Cariba. Elaborado por Damien Marken

Los estudios regionales del 2009 se concentraron en los sitios de La Cariba y El Achiotal. La Cariba (figura 7) es un sitio cercano a La Corona $(4 \mathrm{~km})$ que consta de varios grupos de estructuras ubicados en elevaciones cársticas. El grupo principal se localiza en una de estas elevaciones, la cual fue modificada en la forma de un gran basamento, sobre el cual se colocó un grupo de estructuras formando una plaza abierta en su lado norte. Al este se localiza la estructura principal, que se eleva unos $8 \mathrm{~m}$ sobre la plaza. La elaboración del mapa de La Cariba estuvo a cargo de Damien Marken, cuyo equipo recorrió los alrededores y ubicó varios grupos residenciales. Durante la limpieza del grupo principal se des- 
cubrió un monumento, posiblemente un fragmento de altar, en el acceso norte del basamento. Aunque el relieve está bastante erosionado, se puede distinguir una figura principal acompañada de una mujer a su lado derecho. El texto, parcialmente legible, presenta una fecha de 9 Ajaw 18 Xul (9.15.15.0.0., 746 d.C.). Sobre la estructura que delimita el grupo en la esquina sureste se encontró otro fragmento de monumento donde se observa un pie de perfil y la parte inferior de una columna de glifos.

Otros sitios, El Junquillal (13 km al este de La Corona) y El Ramonal (14.5 km al noreste de La Corona), se registraron con GPS. Estos parecen haber sido sitios del periodo Clásico del mismo tamaño que La Cariba, posiblemente dentro de la esfera de influencia política de La Corona. La investigación regional permitirá establecer la manera en que este último lugar mantuvo el control de su región circundante y los cambios sociopolíticos ocurridos a finales del siglo vil d.C., como consecuencia de la caída del dominio de Calakmul en el norte de Petén.

El otro sitio que contó con investigaciones formales fue El Achiotal (figura 8), cuyo subproyecto estuvo a cargo de Mary Jane Acuña y Carlos Chiriboga. Tomando como referencia algunas visitas anteriores al lugar, ya se había determinado que El Achiotal corresponde a un sitio con ocupación preclásica, por lo que se esperaba incorporar el área de La Corona a los procesos culturales y sociopolíticos ya definidos para esa época.

Las investigaciones en El Achiotal incluyeron la elaboración del mapa del Grupo Principal y el registro de excavaciones de saqueo en las estructuras principales. Los resultados preliminares indican que el sitio tuvo su ocupación más importante durante el Preclásico Tardío, aunque sus orígenes pueden remontarse al Preclásico Medio.

El Grupo Principal del sitio fue construido sobre un escarpe natural de roca caliza y contiene varias estructuras arregladas alrededor de una plaza alargada, orientada en un eje norte-sur. En el límite sur se encuentra la Estructura 1, que es un edificio piramidal de $17 \mathrm{~m}$ de alto, y en el límite norte contiene un conjunto palaciego tipo acrópolis. Los estudios cronológicos se basaron mayormente en pozos de sondeo y en el registro de los túneles de saqueo de la Estructura 1 , donde se pueden observar numerosos pisos y subestructuras, las cuales también presentan remodelaciones arquitectónicas realizadas a lo largo del periodo Preclásico Tardío.

Un hallazgo relevante es la presencia de un mural pintado de rojo (figura 9), colocado en el muro exterior de una de las subestructuras. La pintura representa un bulto ceremonial rodeado de volutas, y combina elementos olmecas y mayas, aunque con un estilo particular de forma geométrica. El bulto tiene una cara antropomorfa, con ojo en forma de $u$ y el símbolo trifoliar huunal en su frente. En la parte inferior presenta un nudo, con un elemento trifoliar. Es interesante que la última etapa constructiva corresponda al Clásico Temprano, indicando así que el sitio no sufrió de un abandono, como se ha registrado en otras zonas de las Tierras Bajas. 


\section{Estudios de ecología}

En 2009 se iniciaron los estudios que permitirán reconstruir las características ambientales de la región de La Corona en tiempos prehispánicos. Estas investigaciones están a cargo de Peter Douglas, quien aplicará métodos de investigación que no han sido utilizados en el área maya. Éstos van dirigidas a establecer los cambios en niveles de precipitación durante la ocupación prehispánica de La Corona y sus alrededores. Para ello, analizará lípidos (fatty acids) de las plantas encontradas en los sedimentos de sibales y otros cuerpos de agua. Estos lípidos han sido definidos como indicadores directos de aumento o disminución de lluvia. Según Douglas, este análisis es más eficiente que el de densidad de sedimentos o de proporciones de isótopos de oxígeno en las conchas de los

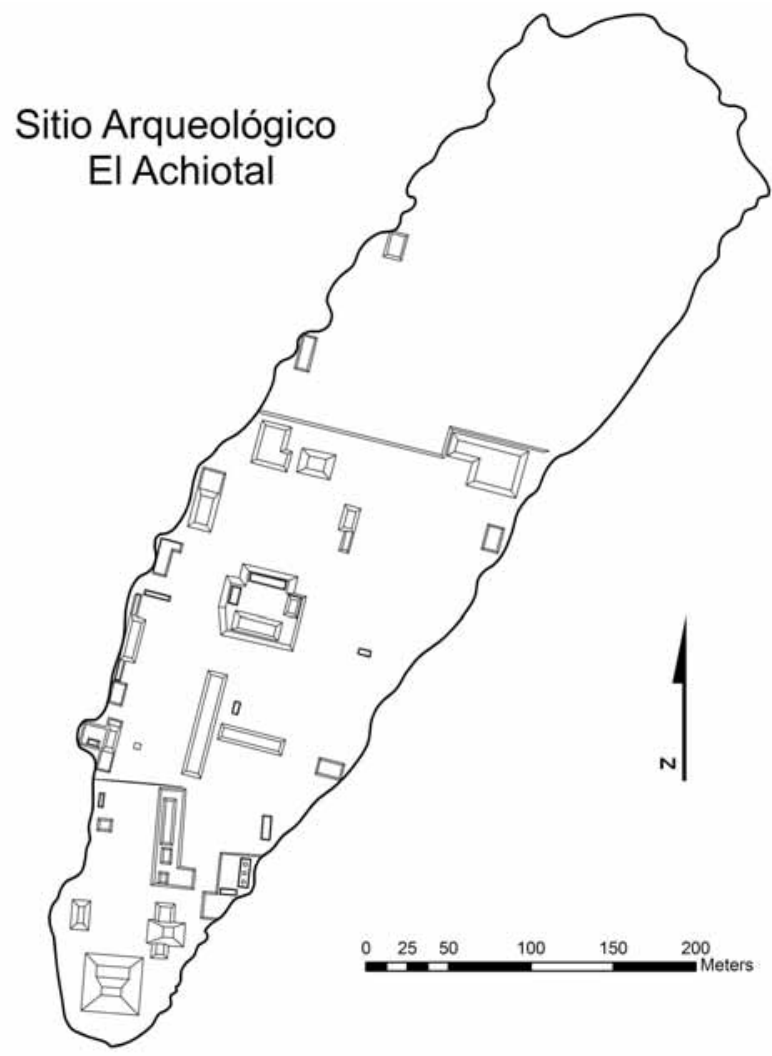

Sitio Arqueologico El Achiotal Mapa Esquemático Julio 2009

Elaborado por: CRC

Figura 8. El Achiotal. Mapa: Carlos Chiriboga 


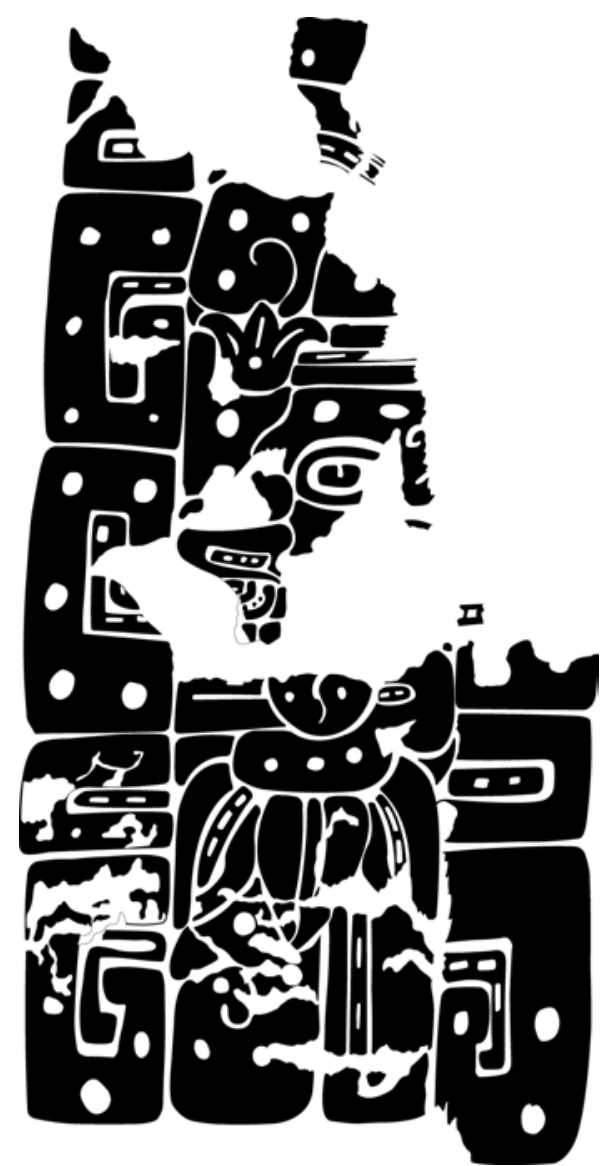

Figura 9. Mural, Estructura Jonon, El Achiotal. Dibujo: Mary Jane Acuña

gasterópodos, ya que estos dos tipos de análisis solamente miden fluctuaciones en el nivel de agua de lagos, y no necesariamente la falta de precipitación pluvial. En este caso, hay que tomar en cuenta que el aumento de vegetación en los alrededores de los cuerpos de agua (posiblemente causado por la disminución de actividad agrícola) puede absorber más cantidad de agua y, por lo tanto, causar un descenso en el nivel del lago. Douglas ha aplicado el análisis de lípidos a las muestras de sedimentos tomadas en Yucatán, y sus resultados preliminares no coinciden con los obtenidos a través de la densidad de sedimentos y gasterópodos. Aunque ambos métodos definen épocas con poca agua, las fechas difieren en unos dos siglos, es decir, que la época con menor precipitación se define entre los años 1200 y 1400 d.C., y no entre el 800 y el 1000 d.C., como se ha propuesto en diversas publicaciones (Hodell et al., 1995; Hodell et al., 2007). 
Los trabajos realizados por el equipo de Douglas incluyeron la toma de muestras de sedimentos en dos sibales de la región, uno de ellos en La Corona (Laguna Alargada) y otro hacia el sur (Dos Cuerpos de Agua). Para ello contaron con una balsa desmontable a la cual se le colocaba el barreno que toma los núcleos o columnas de sedimento. Las muestras fueron trasladadas a la Universidad de Minnesota, donde serán analizadas en los próximos meses.

\section{El sitio de La Corona}

De las investigaciones hasta ahora realizadas se ha definido que La Corona presenta un patrón de asentamiento asociado con las orillas de lagunas y bajos, que son abundantes en la zona. De hecho, se puede notar que el conjunto arquitectónico de La Corona está ubicado en el centro de varias lagunas y sibales, dando la impresión de un sitio defensivo, protegido en todos los lados por el agua (figura 10). El mapeo demostró que el centro arquitectónico del sitio está compuesto por cuatro grupos monumentales.

Al oeste está el Grupo Principal, que consiste en una plaza con seis estructuras monumentales y cinco monumentos con inscripciones (figura 11). Está dominada al oeste por la Estructura 13Q-4, un palacio tipo acrópolis donde vivía la familia real de La Corona. Es probable que el nombre de esta plaza en tiempos antiguos fuera identificado con el toponímico sak nikte’. Además, se han identificado tres escalinatas jeroglíficas que están relacionadas con las estructuras de este grupo.

$\mathrm{Al}$ este se halla el Grupo Coronitas, que consiste en un conjunto de cinco templos alienados norte-sur (figura 12). Por su forma, altura y alineación, se propone que son templos, posiblemente santuarios, que hospedaron las imágenes o ídolos de los dioses patronos del sitio.

Entre estos grupos se encuentran varias estructuras monumentales y grupos residenciales de alto rango. Vale la pena mencionar que en el norte se encuentra la Estela 1 que se fecha para el reino de Chak Ak'aach Yuk, el hermano menor de K'ínich ¿? Yook. Más allá del núcleo del sitio, se han identificado otras concentraciones de asentamiento consistiendo mayormente en estructuras residenciales.

\section{Excavaciones en La Corona}

\section{Estudios arquitectónicos}

Las excavaciones en las estructuras de La Corona se iniciaron tanto en la Plaza Principal como en Coronitas. Estos dos grupos de plaza poseen una planificación distinta, lo que ha llevado a sugerir que tuvieron distintas funciones. La Plaza Principal tiene un diseño más regular, siendo similar a otros sitios, por lo que pudo tener un carácter más público. En cambio, Coronitas tiene un diseño 


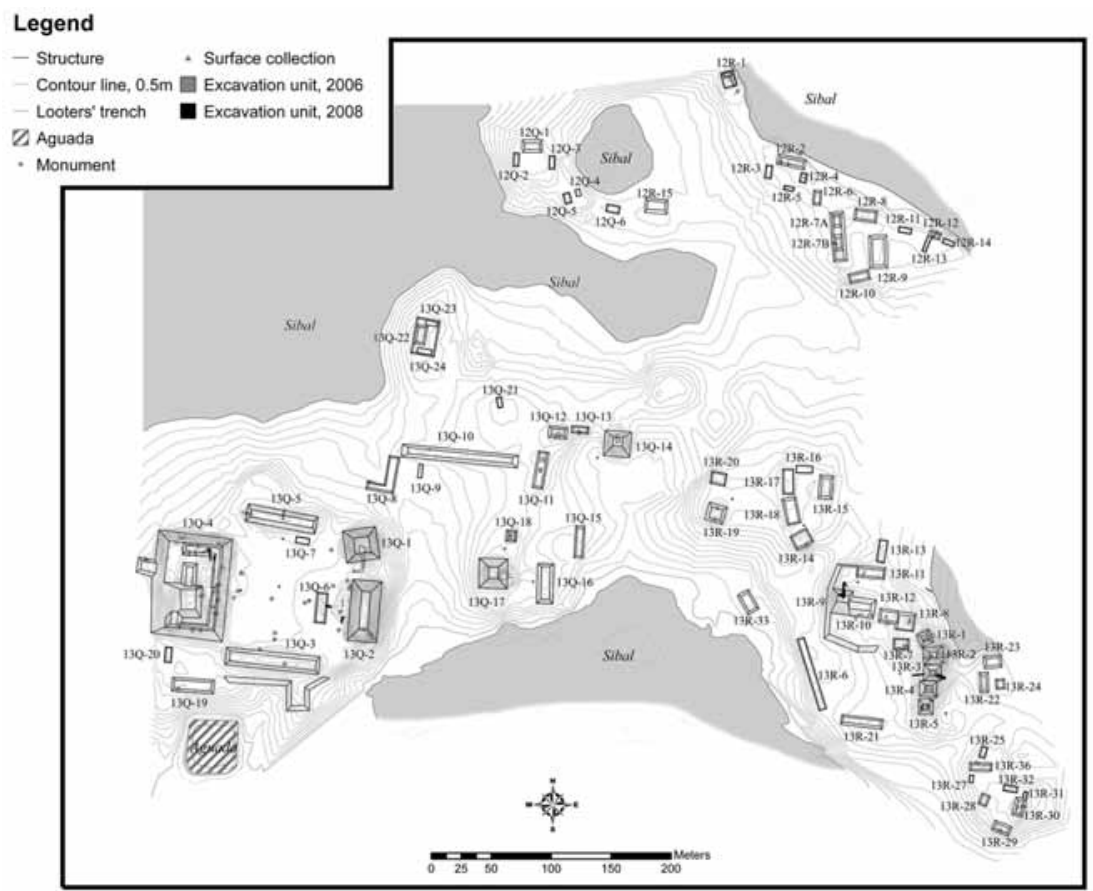

Map by Damien Marken, 2008

Figura 10. La Corona, 2008.

Mapa: Damien Marken

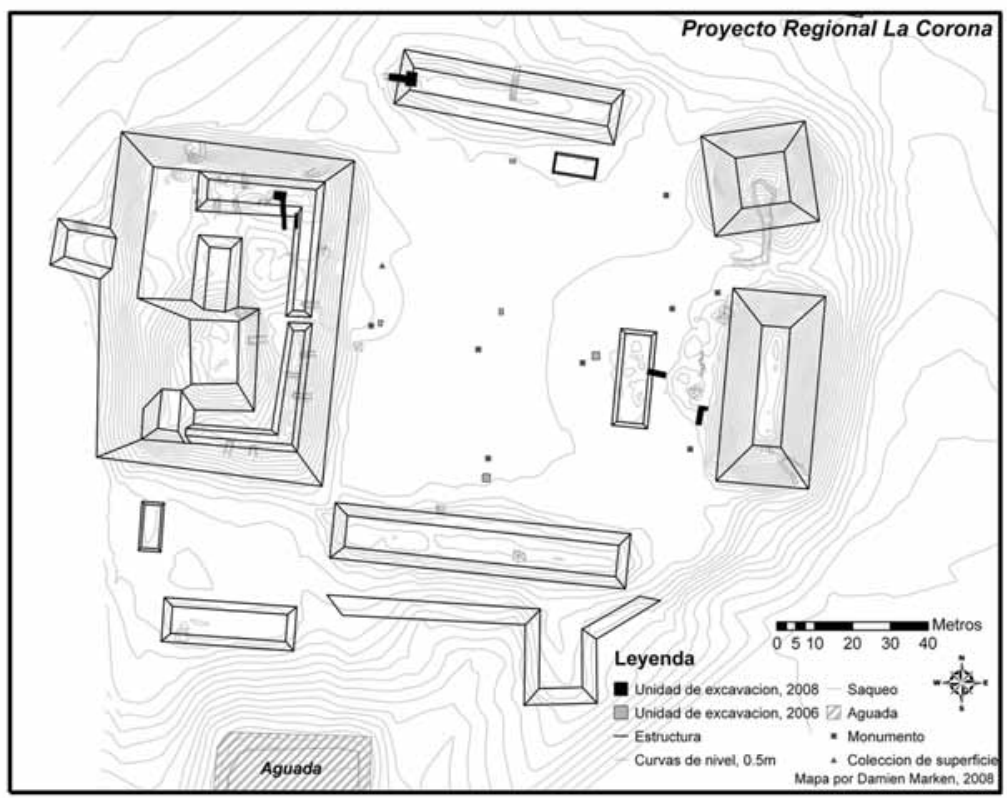

Figura 11. Grupo Principal, La Corona. Mapa: Damien Marken 
bastante irregular, tal vez para actividades rituales de tipo más restringido y asociadas con deidades patronales del sitio. Hay que tomar en cuenta también que Coronitas no contiene monumentos como altares y estelas, solamente los pequeños paneles dentro de los edificios.

\section{Investigaciones en la Plaza Principal}

En la Plaza Principal, Liliana Padilla estuvo a cargo de los trabajos en el Palacio (Estructura 13Q-4), que incluyeron dos pozos estratigráficos en uno de los patios interiores y varias calas y trincheras en la fachada este del edificio. Se realizó una trinchera principal en el eje del edificio, con el objeto de exponer la escalinata de acceso así como otros rasgos arquitectónicos. De hecho, se pudieron observar varias gradas, pero en mal estado de conservación, así como las jambas del pasillo central de la Estructura 13Q-4AB, que funcionó seguramente como acceso principal al conjunto arquitectónico. Se corroboró también la existencia de una escalinata anterior, que aún conserva su repello de estuco. Estas excavaciones no encontraron ninguna evidencia de la Escalinata Glífica 3, por lo que ahora se supone que pudo ubicarse en alguna de las superestructuras que se ubican sobre el basamento. En cuanto a los pozos estratigráficos, se encontró una secuencia de cuatro pisos estucados, correspondientes a varias remodelaciones. Bajo el último se descubrió un relleno de gran tamaño y un muro en talud que pareciera ser

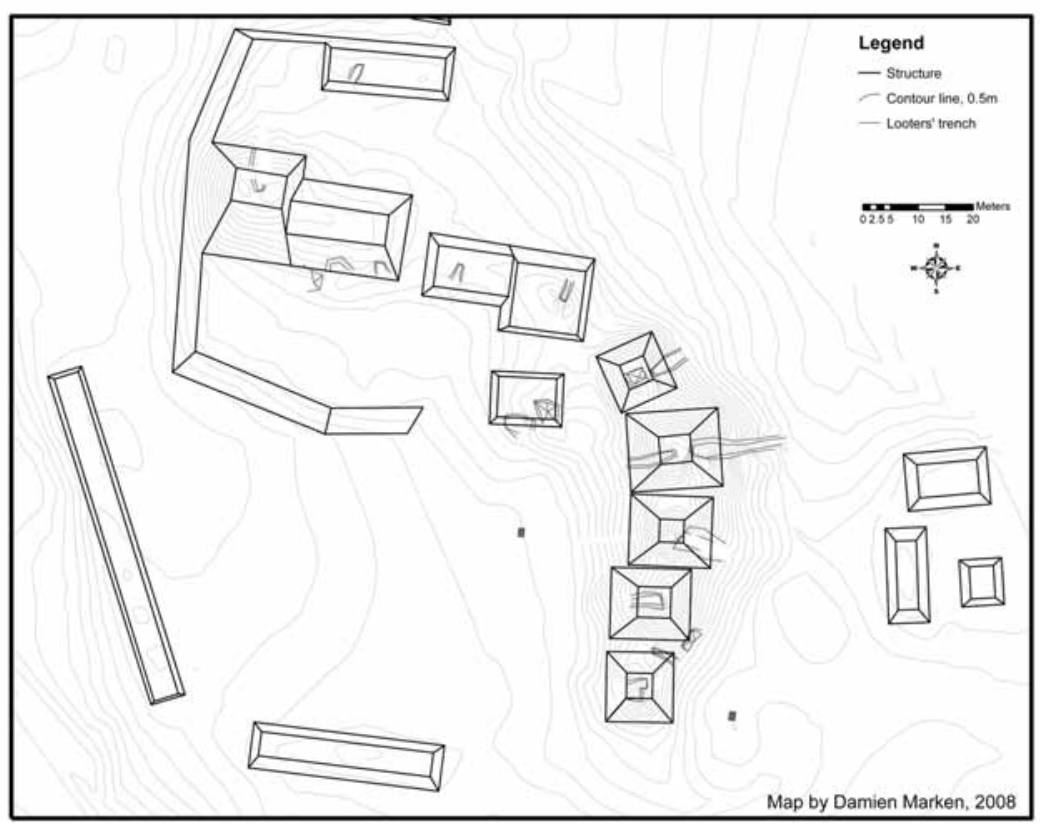

Figura 12. Grupo Coronitas, La Corona. Mapa: Damien Marken 
de contención, aunque es posible que sea parte de una estructura temprana. De cualquier forma, la cerámica recuperada en estos contextos indica que existió una versión del Palacio para el Clásico Temprano, cuyas dimensiones eran de carácter monumental. Dado que la cerámica estaba mezclada con algunos tiestos preclásicos, se especula que puede haber una estructura del Preclásico Tardío.

Las excavaciones en la Estructura 13Q-2 estuvieron a cargo de Stanley Guenter y Cristina Guirola, y se enfocaron en exponer la esquina noroeste del basamento y la parte central de la superestructura. Las excavaciones en la parte superior descubrieron un incensario posclásico, evidenciando así actividades posteriores al abandono en el sitio. Al continuar, se pudo exponer lo que parece ser la cámara central de la superestructura, con un gran muro posterior y pequeñas columnas en la parte frontal. La arquitectura es de buena calidad, y se encontraron repellos y un piso de estuco bien conservado. Los trabajos en el basamento lograron exponer la esquina noroeste, así como parte del muro frontal, el cual ha sido dañado por las excavaciones de saqueo.

Frente a la Estructura 13Q-2 se encuentra la pequeña Plataforma 13Q-6: se había sugerido que formaba parte de una cancha para juego de pelota. No obstante la alta perturbación causada por innumerables pozos y trincheras de saqueo, las excavaciones de Guenter lograron definir algunos pocos rasgos arquitectónicos, incluyendo las esquinas noreste y noroeste, así como algunos alineamientos de piedras en la fachada este. Aunque no se ha definido por completo esta plataforma, lo expuesto hasta ahora sí insinúa la existencia de una cancha. La alta cantidad de saqueo en 13Q-6 también sugiere que allí pudo ubicarse la Escalinata Glífica 2, que contenía figuras de jugadores de pelota.

Las excavaciones en la Estructura 13Q-3 a cargo de Yann Desailly-Chanson se ubicaron en el eje central, donde ya se habían ubicado varios bloques que conformaban la Escalinata Glífica 1. Al exponerse la escalinata central, se descubrieron cuatro bloques tallados con glifos in situ, confirmando así que dicha escalinata glífica se encontraba en el acceso principal del edificio. Esta escalinata es bastante particular, ya que cada bloque es muy pequeño y contiene un solo glifo tallado. En total, se recuperaron 63 bloques, todos ellos muy erosionados y la mayoría fuera de su lugar original. La lectura de algunos bloques indica que esta escalinata trataba de temas bélicos, en especial aquellos con la presencia de títulos asociados con prisioneros.

\section{Investigaciones en el Grupo Coronitas}

En cuanto a la investigación del Grupo Coronitas, los trabajos se enfocaron en la Estructura 13R-3 (a cargo de Joanne Baron) y la Estructura 13R-9 (a cargo de Érika Gómez). La Estructura 13R-3 corresponde al templo piramidal que ocupa el lugar central en el conjunto de cinco templos: tres templos en fila (figura 13) con dos más agregados en ambos lados. Su estado de conservación es bastante malo, debido a una gran trinchera de saqueo en su parte posterior que fue investigada 


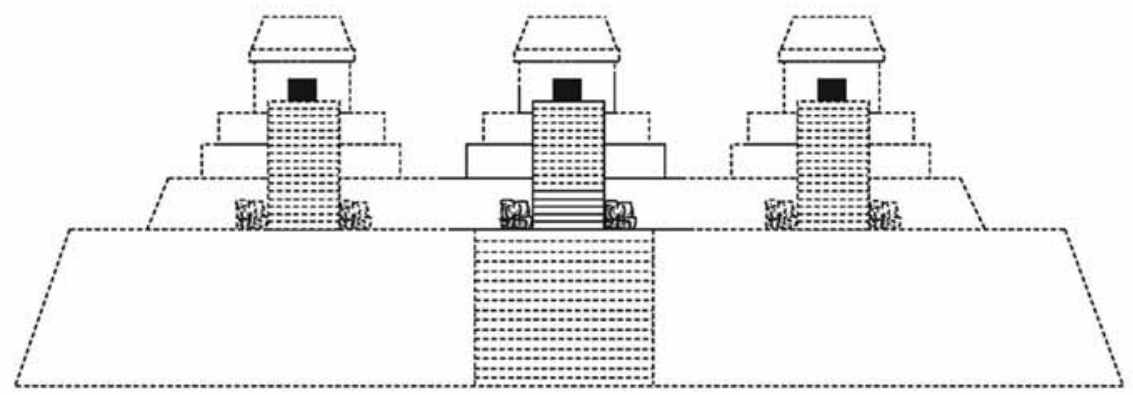

Figura 13. Esquema de los tres templos 13R-2, 3, y 4.

Dibujo: Joanne Baron

por Baron en el 2008. Las excavaciones en el 2009 terminaron de exponer la escalinata principal de acceso, y se definieron algunos rasgos como los cuerpos superiores y el muro lateral de escalinata. En estos trabajos se expuso parte de un mascarón estucado, que sirvió como elemento decorativo del edificio. Las investigaciones en la superestructura apenas pudieron definir algunos rasgos, ya que un árbol de ramón había crecido en este punto. Al removerse las raíces se pudo distinguir parte del acceso al templo que se ubicaba sobre el basamento piramidal. En general, la arquitectura de 13R-3 es de calidad pobre y parece que su construcción se fecha para el Clásico Tardío, sin ninguna evidencia de subestructuras anteriores.

Las excavaciones en la Estructura 13R-9 continuaron las investigaciones iniciadas por Acuña en el 2006 y el 2008 (Acuña, 2006, 2008), solamente que en el 2009 se investigó la parte frontal del edificio. La definición de la escalinata de acceso fue difícil por el alto grado de erosión que sufrió el edificio. Además se constató que esta estructura fue sujeta a numerosas remodelaciones, más que todo en la forma de agregados sobre la escalinata. Las excavaciones en la parte superior de la estructura expusieron una ofrenda en forma de escondite, que fue sellada por un piso de estuco. La ofrenda consistió de un vaso cilíndrico policromado del tipo Mataculebra, cuyo diseño incluye una banda de pseudoglífos y una cabeza del dios K'awiil. Además, el escondite incluyó distintos tipos de conchas y caracoles, así como un mosaico de finas piezas talladas en concha nácar. Había también fragmentos de coral, espinas de raya, un bifacial angosto de pedernal y cuatro navajas de obsidiana sin uso.

\section{Conclusiones preliminares e interrogantes}

Como se mencionó anteriormente, los datos epigráficos han servido para formular una cronología dinástica en La Corona, pero tal información histórica no repre- 
senta toda la historia del sitio ni de la región. Por lo tanto, uno de los objetivos del proyecto ha sido corroborar dicha información y complementarla, especialmente en aquellas épocas previas y posteriores al auge escultórico de La Corona.

En cuanto al Preclásico, ya se mencionó que se tienen datos importantes en El Achiotal y es posible que haya sido el sitio más grande de la región para esta época. No obstante, algunos pozos de sondeo en La Corona han confirmado que este sitio también fue ocupado durante el Preclásico Tardío (Acuña, 2006), pero no se tienen datos de cual pudo ser su extensión. Además la cerámica proveniente del sitio Los Perros también corresponde a esta época y confirma que hubo una ocupación preclásica al norte de La Corona. Cabe destacar que los datos de El Achiotal indican que la afiliación cerámica de la región corresponde a la llamada esfera Chicanel, ya que se han identificado los tipos diagnósticos como Sierra Rojo. Ahora bien, si se toman en cuenta el patrón del eje norte-sur, la aparente ausencia de Grupo E y el estilo geométrico del mural, El Achiotal parece no conformarse a los patrones ya definidos para las ciudades más importantes y mejor investigadas de las Tierras Bajas. Con esto, se abre la posibilidad de que la región noroccidental de Petén pueda presentar formas locales de expresiones arquitectónicas y artísticas, sugiriendo a su vez que no formaron parte de la esfera política de la región de El Mirador.

El otro aspecto que vale la pena resaltar es la evidencia de continuidad de ocupación en los tres sitios con cerámica preclásica. Tanto El Achiotal, como La Corona y Los Perros presentan evidencias relacionadas con el Clásico Temprano, con cerámica y arquitectura asociadas. Por lo tanto, la evidencia de la zona no apoya la idea de un "colapso" general de las Tierras Bajas al final del Preclásico, sino parece indicar el desarrollo de procesos locales distintos para cada región, que más bien podrían explicarse como fluctuaciones en las esferas de dominio de los principales centros, y como falta de una integración política fuerte entre las distintas regiones.

Fase Ek (300-600 d.C.)

El Clásico Temprano en La Corona y su región circundante demuestra entonces antecedentes preclásicos, lo cual indica un proceso gradual de evolución sociopolítica y de crecimiento poblacional. No obstante, el desconocimiento general de la geopolítica de las Tierras Bajas en esta época limita considerablemente la interpretación de La Corona y su consolidación como centro rector del área. Las discusiones relacionadas con el Clásico Temprano tienden a girar en torno al apogeo de Tikal y la relación con Teotihuacan (Laporte, 1995; Stuart, 2000), pero se sabe poco de lo que sucedía en otras regiones. En el caso de La Corona, se ha registrado evidencia arquitectónica de buena calidad para este periodo (Estructura 13Q-5 y Palacio 13Q-4), la cual indica que contaba con recursos y una población significativa. Es posible que toda la Plaza Principal se haya construido en el Clásico Temprano y que las remodelaciones posteriores hayan sido mínimas. 
Los datos arqueológicos, aunque todavía escasos, presentan ya un panorama asociado con la llegada de la señora Ix Naah Ek en el año 520 d.C., en el cual La Corona ya era un centro importante, con arquitectura monumental y seguramente dominante de la región. Ahora bien, si se toma en cuenta que en este momento la capital del reino Kan se encontraba en Dzibanché y no en Calakmul, entonces resulta difícil encontrar las razones que pudieron llevar a concretar una alianza matrimonial y política entre dos centros tan distantes. Habrá que cuestionar la naturaleza de este evento retrospectivo registrado en el Panel 6, y considerar si sucedió en otro sitio más cercano a la región de Dzibanché en Quintana Roo.

\section{Fase Yuknoom (600-700 d.C.)}

Este periodo corresponde a la "época dorada" de inscripciones en La Corona, que también coincide con la fase cerámica Tepeu 1 de las Tierras Bajas. En general, la fase se relaciona con los dos grandes gobernantes de Calakmul, Yuknoom Ch'een y Yuknoom Yich'ak K'ak, quienes conformaron una red de alianzas que dominó casi todas las Tierras Bajas, pero que terminó con el resurgimiento de Tikal como rival principal del reino Kan. Los gobernantes de La Corona aprovecharon su relación de parentesco con la dinastía de Calakmul para erigir nuevas construcciones y consolidar su poder, tal como se refleja en la gran cantidad de paneles y escalinatas con inscripciones. Fue en este momento cuando se construyó el Grupo Coronitas, posiblemente como recinto dedicado a las deidades patronales del lugar y cuyo arreglo arquitectónico es bastante distinto a la Plaza Principal. Las excavaciones en la Estructura 13R-9 han proporcionado fechamientos cerámicos en contextos sellados, que han permitido identificar las primeras etapas constructivas, como es el caso de una ofrenda de un vaso tipo Mataculebra y un relleno que contiene diversos tipos policromados correspondientes a la fase Tepeu 1.

Fase Kantemo (700-800 d.C.)

Finalmente, la fase final de ocupación de La Corona corresponde al siglo vil d.C., que también coincide con Tepeu 2 (700-800 d.C.). En esta época la arquitectura pierde calidad, pero se notan algunos patrones locales que sugieren una mayor autonomía política y posiblemente un mayor grado de control local. Por ejemplo, se abandona el patrón de monumentos pequeños y se observa un cambio hacia el uso de estelas y altares de tamaño mayor, tal como en otros sitios contemporáneos de otras zonas de las Tierras Bajas. No obstante, el descubrimiento de un monumento en La Cariba también apunta hacia un proceso de descentralización política. Para este periodo se registra la llegada de una tercera mujer desde Calakmul, urbe que a pesar de su debilitamiento general todavía mostraba presencia a través de este tipo de alianzas. Hasta el momento se sabe poco de la ocupación final y abandono de La Corona, aunque la última fecha registrada 
está en el Altar 4 y corresponde al año 805 d.C. Supuestamente a comienzos del siglo ix d.C. el sitio fue absorbido por los procesos de colapso que se empezaban a propagar desde la región sur y occidental del Petén.

Cabe mencionar que la pervivencia de La Corona hasta inicios del siglo ix d.C. indica que el debilitamiento de Calakmul, a pesar de provocar algunos cambios, no tuvo efectos mayores en su desarrollo. Por lo tanto, en vez de haberse establecido una relación de dependencia respecto a Calakmul, la evidencia indica que La Corona se consolidó como un centro importante en la región en los siguientes 100 años.

\section{El futuro de la región noroccidental de Petén}

Como se ha constatado con los resultados de las investigaciones pasadas y las realizadas en el 2009, La Corona es un sitio arqueológico que tiene un alto potencial para responder a algunos de los principales cuestionamientos en la arqueología maya. Sin embargo, el futuro del sitio se ve amenazado por problemáticas de índole mayor en la región noroccidental de Petén, como lo es el narcotráfico, las invasiones de áreas protegidas y la quema de bosques. Por lo tanto, el Proyecto Regional Arqueológico La Corona se ha unido a los distintos esfuerzos para poder conservar los recursos naturales y culturales de la región, para así continuar las investigaciones y frenar la depredación en el sitio.

\section{BIBLIOGRAFÍA}

Acuña, Mary Jane

2006 "CR-ES: excavaciones de sondeo en los Grupos A, B, y C de La Corona", "Proyecto Arqueológico El Perú-Waka': informe no. 4, temporada 2006", pp. 457-478, H. Escobedo y D. Freidel (eds.). Dallas, Texas: Southern Methodist University.

2008 "CR-11A: limpieza de trinchera de saqueo en la Estructura 13R-9", "Proyecto Regional Arqueológico La Corona no. 1, temporada 2008”, pp. 109-128, M. Canuto y T. Barrientos (eds.). New Haven, Connecticut/Guatemala: Yale University/Universidad del Valle de Guatemala.

Canuto, Marcello A. y Tomás Barrientos Q. (eds.)

2009 "Proyecto Arqueológico La Corona. Informe temporada 2008". New Haven, Connecticut/Guatemala: Yale University/Universidad del Valle de Guatemala. <http://www.mesoweb.com/resources/informes/LaCorona2008.html>. [Consultada el 25 de abril del 2011.]

Canuto, Marcello, Stanley Guenter, Evangelia Tsesmeli y Damien Marken

2005 "El Reconocimiento de La Corona, 2005”. Manuscrito. Instituto de Antropología e Historia, Guatemala. 
Canuto, Marcello, Stanley Guenter, Mary Jane Acuña, Ellen Bell y Damien Marken

2006 "El Reconocimiento de La Corona, 2006". Manuscrito. Instituto de Antropología e Historia, Guatemala.

Chase, Arlen F. y Diane Z. Chase

1998 "Late Classic Maya Political Structure, Polity Size, and Warfare Arenas", Anatomía de una civilización: aproximaciones interdisciplinarias a la cultura maya, pp. 11-29, A. Ciudad Ruiz, Y. Fernández, J. M. García, J. Iglesias, A. Lacadena y L. Sanz (eds.). Madrid: Sociedad Española de Estudios Mayas (Publicaciones de la S.E.E.M, 4).

Coe, Michael

1973 The Maya Scribe and His World. Nueva York: Grolier Club.

Esparza Olguin, Octavio Q. y Vania E. Pérez Gutiérrez

2009 "Archaeological and epigraphic studies in Pol Box, Quintana Roo", PARI Journal, 9 (3): 1-16. San Francisco: Pre-Columbian Art Research Institute.

Freidel, David A. y Héctor Escobedo (eds.)

2004 "Proyecto Arqueológico El Perú-Waka’: informe no. 1, temporada 2003". <http://www.mesoweb.com/resources/informes/Waka2003.html>. [Consultada el 25 de abril del 2011.]

2005 “Proyecto Arqueológico El Perú-Waka': informe no. 2, temporada 2004". $<$ http://www.mesoweb.com/resources/informes/Waka2004.html >. [Consultada el 25 de abril del 2011.]

2006 “Proyecto Arqueológico El Perú-Waka’: informe no. 3, temporada 2005”. <http://www.mesoweb.com/resources/informes/Waka2005.html >. [Consultada el 25 de abril del 2011.]

2007 "Proyecto Arqueológico El Perú-Waka': informe no. 4, temporada 2006". <http://www.mesoweb.com/resources/informes/Waka2006.html>. [Consultada el 25 de abril del 2011.]

Freidel, David A. y Stanley Guenter

2003 "Bearers of War and Creation"; Archaeology. A publication of The Archaeological Institute of America. <http://www.archaeology.org/online/features/siteq2/ index.html $>$. [Consultada el 25 de abril del 2011.]

Graham, Ian

1988 "Homeless Hieroglyphs”, Antiquity, 62 (234): 122-126. York: University of York.

1997 "Mission to La Corona”. Archaeology, 50 (5): 46. Boston: Archaeological Institute of America.

2002 "Mission to La Corona: A New Maya Site May Fail to Qualify as Site Q", Secrets of the Maya, pp. 78-79, P. Young (ed.). Londres: Hatherleigh Press.

Grube, Nikolai

2004 "El origen de la dinastía Kaan", Los cautivos de Dzibanché, pp. 117-131, E. Nalda (ed.). México: Consejo Nacional para la Cultura y las Artes/Instituto Nacional de Antropología e Historia. 
Grube, Nikolai

2005 "Toponyms, Emblem Glyphs, and the Political Geography of Southern Campeche", Contributions to Maya Archaeology, pp. 87-100, I. Šprajc (ed.). Ljubljana, Eslovenia: Slovene Anthropological Society (Anthropological Notebooks).

Grube, Nikolai e Iken Paap

2006 "Informe: trabajos de exploración en Uxul (Campeche), 9-15 marzo de 2006". Bonn: Institut für Altamerickanistik und Ethnologie der Universität Bonn. 2007 "Informe: trabajos de levantamiento topográfico en Uxul (Campeche), 23 de marzo-25 de abril de 2007". Bonn: Institut für Altamerickanistik und Ethnologie der Universität Bonn.

Guenter, Stanley

2005 "La Corona Find Sheds Light on Site Q Mystery", The PARI Journal, 6 (2): 1618. San Francisco: Pre-Columbian Art Research Institute.

Hansen, Richard D.

1997 "Plundering the Peten", Archaeology, 50 (5): 48-49. Boston: Archaeological Institute of America.

Hellmuth, Nicholas M.

1996 Iconography of Seven Maya Ballplayers: Rio Usumacinta or Calakmul? Providence, Rhode Island: Foundation for Latin American Anthropological Research.

Houston, Stephen D. y David Stuart

2001 "Peopling the Classic Maya Court", Royal Courts of the Ancient Maya, Volume 1: Theory, Comparison, and Synthesis, pp. 54-83, T. Inomata y S. Houston (eds.). Boulder, Colorado: Westview Press.

Hodell, David A., Mark Brenner y Jason H. Curtis

2007 "Climate and Cultural History of the Northeastern Yucatan Peninsula, Quintana Roo, Mexico”, Climatic Change, 83: 215-540. Palo Alto, California: Stanford University.

Hodell, David A., Jason H. Curtis y Mark Brenner

1995 "Possible role of climate in the collapse of Classic Maya civilization", Nature, 375: 391-394. Nueva York: Nature Publishing Group/Mcmillan Publishers

Kaufman, Frederick y Marco A. Leal

1988 Proyecto arqueológico peruano-guatemalteco al noroccidente de Petén, Guatemala. Guatemala/Lima: Universidad de San Carlos de Guatemala/Consejo de Ciencia y Tecnología del Perú/Instituto de Arqueología Amazónica.

Laporte, Juan Pedro

1995 "Preclásico a Clásico en Tikal: proceso de transformación en Mundo Perdido", The Emergence of Lowland Maya Civilization, pp. 17-34, N. Grube (ed.). Möckmühl, Alemania: Verlag Anton Saurwein (Acta Mesoamericana, 8). 
Leal, Marco A. y Salvador López

1993 Reconocimiento arqueológico en la brecha topográfica Libertad-Xan (sector Tamariz-Río San Pedro). Guatemala: Basic Resources Int.

Leal, Marco A., Salvador López, Teresita Chinchilla, José Paredes, José Benítez y Mario Zetina

1988 Reconocimiento arqueológico en el noroccidente de Petén. Guatemala: Universidad de San Carlos de Guatemala, Escuela de Historia, Instituto de Investigaciones Históricas, Antropológicas, y Arqueológicas (Serie Informes, 1).

Marcus, Joyce

1973 "Territorial Organization of the Lowland Classic Maya”, Science, 180: 911-916. Washington, D.C.: American Association for the Advancement of Science.

1976 Emblem and State in the Classic Maya Lowlands: An Epigraphic Approach to Territorial Organization. Washington, D. C.: Dumbarton Oaks.

Marken, Damien y Stanley Guenter

2007 "Monumentos y reconocimiento en La Corona: 2006", "Proyecto Arqueológico El Perú-Waka': informe no. 4, temporada 2006”, pp. 479-490, H. Escobedo y D. Freidel (eds.). Dallas, Texas: Southern Methodist University.

Martin, Simon

1996 “Calakmul y el enigma del glifo “Cabeza de Serpiente'”, Arqueología Mexicana, 3 (18): 42-45. México: Instituto Nacional de Antropología e Historia/Raíces.

1997 "The Painted King List: A Commentary on Codex-Style Dynastic Vases", The Maya Vase Book Vol. 5, pp. 846-867, B. Kerr y J. Kerr (eds.). Nueva York: Kerr Associates.

2001 "Court and Realm: Architectural Signatures in the Classic Maya Southern Lowlands", Royal Courts of the Ancient Maya, Volume 1: Theory, Comparison, and Synthesis, pp. 168-194, T. Inomata y S. Houston (eds.). Boulder, Colorado: Westview Press.

2004 "Preguntas epigráficas acerca de los Escalones de Dzibanché", Los cautivos de Dzibanché, pp. 105-115, E. Nalda (ed.). México: Consejo Nacional para la Cultura y las Artes/Instituto Nacional de Antropología e Historia.

2008 "Wives and Daughters on the Dallas Altar", Mesoweb <http://www.mesoweb. com/articles/Martin/Wives\&Daughters.pdf > . [Consultada el 25 de abril del 2011.]

Martin, Simon y Nikolai Grube

1995 "Maya Superstates", Archaeology, 48 (6): 41-46. Boston: Archaeological Institute of America.

Mathews, Peter

1979 "Notes on the Inscriptions of 'Site Q'”. Manuscrito. Alberta: University of Calgary.

1988 "Notes on the Inscriptions of 'Site Q'”. Manuscrito. Alberta: University of Calgary. 
Miller, Jeffrey

1974 "Notes on a Stela Pair Probably from Calakmul, Campeche, Mexico", Primera Mesa Redonda de Palenque, Part I, pp. 149-162, M. Robertson (ed.). Pebble Beach, California: Robert Louis Stevenson School.

Nalda, Enrique

2000 "Dzibanché: un primer acercamiento a su complejidad", Guardianes del Tiempo, pp. 37-71, A. Velásquez (ed.). Chetumal/México: Universidad de Quintana Roo/Instituto Nacional de Antropología e Historia.

2004 Los Cautivos de Dzibanché. México: Consejo Nacional para la Cultura y las Artes/Instituto Nacional de Antropología e Historia.

Ringle, William

1985 "Notes on Two Tablets of Unknown Provenance", Fifth Palenque Round Table, 1983, pp. 151-158, V. Fields (ed.). San Francisco: Pre-Columbian Art Research Institute.

Schele, Linda y David A. Freidel

1990 A Forest of Kings: The Untold Story of the Classic Maya. Nueva York: William Morrow and Co.

Schele, Linda y Peter Mathews

1991 "Royal Visits and Other Intersite Relationships among the Classic Maya", Classic Maya Political History: Hieroglyphic and Archaeological Evidence, pp. 226-252, P. Culbert (ed.). Cambridge, Reino Unido: Cambridge University Press.

Schele, Linda y Nikolai Grube

1994 Notebook for the XVIII Maya Hieroglyphic Workshop at Texas: Tlaloc-Venus Warfare: The Peten Wars 8.17.0.0.0-9.15.13.0.0. Austin, Texas: University of Texas, Institute of Latin American Studies.

Šprajc, Ivan

2002- "Maya Sites and Monuments in SE Campeche, Mexico", Journal of Field Ar2004 chaeology, 29 (3-4): 385-407. Leeds, Reino Unido: Maney Publishing.

2008 Reconocimiento arqueológico en el sureste del estado de Campeche, México: 19962005. Oxford: ArchaeoPress (British Archaeological Reports, International Series 1742/Paris Monographs in American Archaeology).

Stuart, David

2000 “'The Arrival of Strangers': Teotihuacan and Tollan in Classic Maya History”, Mesoamerica's Classic Heritage: From Teotihuacan to the Aztecs, pp. 465-514, D. Carrasco, L. Jones y S. Sessions (eds.). Boulder, Colorado: University Press of Colorado.

2001 “Las ruinas de La Corona, Petén, y la identificación del 'Sitio Q'”. Ponencia presentada en el XV Simposio de Investigaciones Arqueológicas en Guatemala, julio del 2001. Guatemala, Guatemala. 
Stuart, David y Stephen D. Houston

1994 Classic Maya Place Names. Washington, D.C.: Dumbarton Oaks (Studies in Pre-Columbian Art and Archaeology, 33).

Stuart, David, Simon Martin y Stephen Houston

2008 “Three Panels from La Corona?” < http://www.mayavase.com/corona/La_Corona.html>. [Consultada el 26 de abril del 2011.]

Velásquez García, E.

2004 "Los Escalones Jeroglíficos de Dzibanché”, Los Cautivos de Dzibanché, pp. 79-103, E. Nalda (ed.). México: Consejo Nacional para la Cultura y las Artes/ Instituto Nacional de Antropología e Historia.

2005 "The Captives of Dzibanche”, PARI Journal, 6 (2): 1-4. San Francisco, California: Pre-Columbian Art Research Institute.

2008 "Los posibles alcances territoriales de la influencia política de Dzibanché durante el Clásico Temprano: nuevas alternativas para interpretar las menciones históricas sobre la entidad política de Kan”, El territorio maya: memoria de la Quinta Mesa Redonda de Palenque, pp. 323-352, R. Liendo Stuardo (ed.). México: Instituto Nacional de Antropología e Historia. 
